\title{
A Systematic Review of Attitudes, Anxiety, Acceptance, and Trust Towards Social Robots
}

\author{
Stanislava Naneva ${ }^{1}$ (D) Marina Sarda Gou ${ }^{1}$ (D) Thomas L. Webb ${ }^{1}$ (D) Tony J. Prescott $^{2}$ (D)
}

Accepted: 12 May 2020 / Published online: 3 June 2020

(c) The Author(s) 2020

\begin{abstract}
As social robots become more common, there is a need to understand how people perceive and interact with such technology. This systematic review seeks to estimate people's attitudes toward, trust in, anxiety associated with, and acceptance of social robots; as well as factors that are associated with these beliefs. Ninety-seven studies were identified with a combined sample of over 13,000 participants and a standardized score was computed for each in order to represent the valence (positive, negative, or neutral) and magnitude (on a scale from 1 to -1 ) of people's beliefs about robots. Potential moderating factors such as the robots' domain of application and design, the type of exposure to the robot, and the characteristics of potential users were also investigated. The findings suggest that people generally have positive attitudes towards social robots and are willing to interact with them. This finding may challenge some of the existing doubt surrounding the adoption of robotics in social domains of application but more research is needed to fully understand the factors that influence attitudes.
\end{abstract}

Keywords Attitudes toward technology $\cdot$ Social robots $\cdot$ Systematic review $\cdot$ Human-robot interaction

\section{Introduction}

According to a widely-reported large-scale survey [1], a substantial proportion of EU citizens have negative attitudes toward the use of robots within healthcare and other fields that are traditionally dominated by humans. There have also been suggestions of a growing anxiety among the public that automation, enabled by robotics, will lead to a significant loss of jobs [2,3]. As we will explore in this article, attitudes toward robots appear mixed, likely depend on the setting and question asked, and in some cases are somewhat divorced from reality (e.g., there is evidence that attitudes are based on science-fiction, rather than objective reality; [4]). While atti-

Stanislava Naneva and Marina Sarda Gou have contributed equally to this work.

Electronic supplementary material The online version of this article (https://doi.org/10.1007/s12369-020-00659-4) contains

supplementary material, which is available to authorized users.

Marina Sarda Gou

msardagou1@sheffield.ac.uk

1 Department of Psychology, The University of Sheffield, Sheffield, UK

2 Department of Computer Science, The University of Sheffield, Sheffield, UK tudes do not consistently predict behaviour, they are thought to influence people's behavioural intentions [5] and therefore may predict the uptake and use of robots alongside other variables such as anxiety, trust, and intention to use and engage with robots. An improved understanding of people's attitudes toward robots should therefore help to inform future research, development, and deployment of robotics in various domains of public and private life.

The present review focuses on social robots, due to their increasing use in various settings such as healthcare, entertainment, and customer service [6-8]. While the idea of robots that can interact socially with people has been around for some time, their use has been relatively limited and less widespread in comparison to, for example, manufacturing robots $[9,10]$. Nevertheless, social robots garner attention from the media and general public alike, and have sparked debate about their potential impact on society $[11,12]$. We define a social robot as a physically embodied artificial agent (i.e., something that has a physical structure that mimics the behaviour, appearance, or movement of a living being-usually a human, but could also be an animal or plant) that: (a) has features that enable humans to perceive the agent as a social entity (e.g., eyes); (b) is capable of interacting with humans via a social interface [13]; and (c) can communicate verbal and/or non-verbal information to humans (see Supple- 
mentary Materials 2). In short, a social robot is an embodied system that can be perceived as a social entity and is capable of communicating with the user [14].

To date, no systematic review has investigated and synthesised the current evidence on people's attitudes toward, trust in, anxiety associated with, and acceptance of social robots. Evidence suggest that all of these beliefs can predict the use of social robots $[15,16]$, and reflect the same broad construct [17-20], which is people's perception or evaluation of robots.

\subsection{Attitudes Toward Social Robots}

Current evidence on people's attitudes toward social robots reveals a somewhat ambiguous picture that makes it difficult to say whether people, in general, have a negative or positive view of social robots. This is, at least to some extent, likely to be due to the variety of contexts in which social robots are employed. People generally agree that, while working alongside robots is not out of the question, robots should not entirely replace humans in jobs that require substantial social skills (e.g., nursing; [21]). At the same time, some studies have found positive attitudes toward robots performing jobs that demand more social skills [1,21]. These inconsistencies merit further investigation.

In addition to providing an overall assessment of the current evidence of people's attitudes toward robots, where possible, the present review will also look at three distinct components of attitude-cognition, affect, and behaviour [22]. Cognitive attitudes reflect people's thoughts—or cognitive evaluations - about the attitude object (e.g., that robots are useful). Affective attitudes reflect the individual's feelings or emotions toward the attitude object (e.g., whether they feel warm toward social robots). Finally, behavioural attitudes reflect people's observable or self-reported behaviours toward an attitude object (e.g., the extent to which they approach and interact with a social robot). Differentiating between the various components of attitude may provide more insight into people's attitudes toward social robots, and potentially account for some of the mixed findings identified in the literature to date (e.g., people may have positive cognitive attitudes, believing that social robots are worthwhile, but have negative affective attitudes, to the extent that they feel uneasy when they think about interacting with a robot).

\subsection{Anxiety About Social Robots}

A number of studies provide evidence that anxiety, alongside attitudes, predicts intentions to use social robots and the quality of people's interaction with social robots [23-25]. Anxiety toward robots is often measured using self-report measures, such as the Robot Anxiety Scale (RAS; [25]) or direct observation of behaviour during human-robot interaction (HRI). Despite the potential importance of anxiety in shaping how people interact with robots, current evidence presents a mixed picture as to how anxious people are about social robots. For example, Nomura, Shintani, Fujii, and Hokabe [26] found that both anxiety and attitudes can affect how people behave during HRI in similar ways, while de Graaf and Allouch [27] found that participants interacting with a robot showed a change in their anxiety but not their attitudes. Therefore, the present review sought to integrate the evidence on anxiety to date, as well as identify factors that might account for the variable estimates in individual studies.

\subsection{Trust in Social Robots}

Trust has also been recognised as a factor that, at least in part, predicts not only the quality of HRI but also how willing people are to use social robots for certain tasks [28]. Trust is likely to be particularly important in relation to social robots, especially in healthcare, where trust has been associated with patient satisfaction and therapeutic effectiveness [29]. So far, reviews have focused on the impact of trust in robots on human-robot interaction, showing that the main factors influencing trust relate to aspects of the robot (e.g., the robot's design and performance) while environmental factors play a more moderate role in how much people trust robots [30]. However, the impact of trust in relation to social robots specifically has not been reviewed [31].

\subsection{Acceptance of Social Robots}

Acceptance is generally defined as the intention to use, and in some cases, as the actual use of robots [15, 32,33]. Compared to anxiety and trust, there is considerably more evidence on the extent to which people accept social robots, particularly in the healthcare and elderly care domains. Acceptance of robots in healthcare has been found to be mixed and can vary considerably depending on the function and appearance of the robot [34]. Despite the potential that social robots have to alleviate the ever-growing demands on healthcare professionals [34, 35], low levels of acceptance can prove detrimental to the development and utilisation of such technology $[34,36]$. Therefore, a broader understanding of the extent to which social robots are accepted in healthcare and other settings; along with factors that are associated with acceptance is needed.

\section{What Factors Influence People's Attitudes Toward Robots?}

Several factors are likely to be associated with people's attitudes toward, trust in, acceptance of, and anxiety toward social robots. For example, people's beliefs may differ as a function of whether they have recently been exposed to social 
robots (e.g., studies that provide direct HRI may report different attitudes to studies where participants do not interact with a robot), the intended domain of application (e.g., companionship and domestic assistance, education, or healthcare), and the design of the robot (e.g., humanoid or anthropomorphic). We expand on these potential factors below.

\subsection{Type of Exposure to Robots}

The way that people think about robots might be affected by whether they are given the opportunity to interact with a robot, directly or indirectly, prior to their attitudes being measured. Studies generally provide participants with at least one of three types of exposure to robots (i.e., HRI):

No HRI Participants were not asked to interact, view, or imagine a social robot or robots (e.g., participants were only asked about their attitudes toward social robots in general; [37]);

Indirect HRI Participants observed a direct interaction or were shown (or asked to imagine) a representation of the social robot or robots (e.g., participants read an illustrated description of a NAO robot; [38]);

Direct HRI Participants interacted with a social robot that was physically present at the same time and place as them (e.g., participants took part in a mock-interview with a Geminoid HI-2 robot; [39]).

\subsection{Domain of Application}

Evidence suggests that people's attitudes toward robots may, to some extent, depend on the domain in which the robot is (or is intended to be) used [40, 41]. For the purposes of this review, we identified six broad domains of application:

\section{Companion Robotics and Domestic Assistance} Robots designed specifically and exclusively to interact socially with humans for a prolonged period of time and to provide companionship (e.g., a study investigates attitudes towards the robots NAO and Darwin; [42]); or robots that are designed to help with domestic chores, as well as provide social interaction (e.g., a study investigating the evaluation of a socially assistive robot in a smart home setting; [43]);

Education Robots Designed to assist educators with teaching and social interaction with students (e.g., a study investigating how students evaluate the use of NAO to teach English lessons; [44]).

Healthcare Robots designed to help patients, doctors or healthcare providers (e.g., a study investigating the attitudes and preferences of staff, residents, and relatives of residents in a retirement village towards a health-care robot; [2]).
Paediatric Care Robots that are used in healthcare but specifically designed to assist children and the healthcare providers who treat them (e.g., an evaluation of physiotherapists' acceptance of assistive robots as a therapeutic aid for children in rehabilitation; [45]).

HRI Robots that are designed primarily to interact with people, with any additional functionality (e.g., providing care) being secondary. For example, playing games or having a conversation (e.g., a study examining the effect of group size on people's attitudes and behaviours toward robots as interaction partners; [46]).

General Application The study does not specify or imply an application domain for the robot or robots being investigated. (e.g., a study investigating the effectiveness of exhibitions of robots as a means of shaping people's beliefs about robots; [47]).

\subsection{Design of Robot}

Design features of robots, such as the degree of humanlikeness, are likely to influence people's attitudes towards robots [31, 48]; however, this influence has not been quantified or reviewed comprehensively so far. The present review therefore categorised each of the robots studied into one of three broad categories:

Humanoid A robot that resembles a human body (e.g., the humanoid robot NAO; [49]).

Anthropomorphic A robot that imitates some parts of the human body and can be subject to anthropomorphisation by the user (e.g., a robot with a human-like face; [50]).

Non-humanoid A robot that resembles any other living organism except for a human or does not imitate a living organism (e.g., Aibo, a robot that resembles a dog; [51]).

\subsection{Geographical Location}

The cultural background and nationality of users may contribute to the variability in people's attitudes toward [52], trust in [20], and acceptance of [53] social robots. The present review therefore compares the geographical locations (i.e., countries) in which the studies took place as an approximation of participants' cultural backgrounds. Enough data was available to compare eight geographical locations: Australia, France, Germany, Italy, Japan, the Netherlands, New Zealand, South Korea, Taiwan, and the United States of America (USA).

\subsection{Sample Characteristics}

Attitudes towards robots also likely vary according to demographic factors such as users' age and gender [48]. For example, men generally tend to have more positive attitudes 
towards robots than women [40]. Similarly, young adults tend to have more positive attitudes toward robots than elderly adults and are more willing to make use of robots [40]. Therefore, the present review investigates whether participants age and gender are associated with their beliefs about robots. In addition, some studies have reported that previous experience with and long-term exposure to robots also affects people's attitudes [54] which is why the present review also attempted to investigate this factor.

\section{The Present Review}

The present review expands on earlier efforts to understand people's beliefs about social robots (e.g. [31, 34, 41, 55]) by taking a broad approach to the collection and synthesis of available literature in order to provide an overview, of not only people's attitudes toward social robots, but also other beliefs which are relevant to the uptake of robotics such as acceptance, anxiety and trust. The review sought to include studies focusing on any type of social robot and a wide variety of domains where they might be used. In addition, we also present a series of analyses that go beyond previous systematic reviews. Specifically, we have developed a novel method for standardising the measures of participants' beliefs about robots in each of the primary studies. This approach enabled us to estimate people's attitudes toward robots, across the available evidence, weighing each estimate by the size of the sample in a manner similar, but not identical, to that of a conventional meta-analysis. ${ }^{1}$ Additionally, by combining estimates of beliefs in specific areas (e.g., studies focusing on social robots in particular contexts), we were able to investigate the factors that are associated with people's attitudes toward robots.

\section{Method}

The review was pre-registered on PROSPERO (CRD42017057331).

\subsection{Systematic Literature Search}

In order to identify studies that measured people's attitudes toward, trust in, acceptance of, and/or anxiety toward social robots, the following databases were searched between January and February, 2018 and repeatedly searched in Jan-

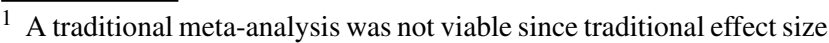
metrics cannot be used to describe the average level of a given variable (e.g., the valence of people's attitudes); only the extent to which it is influenced by a manipulation (e.g., effect size Cohen's $d$ ) or is related to another measure (e.g., effect size $r$ ).
}

uary 2019: PsycINFO and PsycARTICLES (Ovid), IEEE Xplore, ProQuest, and Google Scholar. A separate search was conducted for each of the four measures of interest in each database (except Google Scholar) using the search terms: "[attitud*/accept*/trust*/anxi*] AND (robot* OR "human-robot interaction" OR "assistive robot" OR "social robot") AND participant". A slightly different approach was used for Google Scholar as it was found that the combination of the above search terms did not generate as relevant results as the phrase: "[attitude/acceptance/trust/anxiety] AND robot AND participant". Only articles from the first ten pages of results for each of the four searches conducted in Google scholar were considered in order to ensure that the search was manageable. In order to identify further grey literature, publication lists of relevant research laboratories were also searched (a full list of the laboratories can be found in the review's protocol on PROSPERO). No limitations on publication date were specified for any of the databases. The references of the identified papers were added to and managed via EndNote where duplicates were removed prior to screening the research articles. Figure 1 shows the number of articles that were identified as well as the number of articles that were included and excluded at each stage of the screening process.

\subsection{Screening and Selection of Relevant Papers}

The search results were screened by a member of the research team in two stages and guided by a priori inclusion and exclusion criteria. Any uncertainty as to whether a paper should be included or not was resolved through discussion with the research team.

First, the titles and abstracts of the retrieved research articles were screened in order to identify potentially relevant studies that satisfied our inclusion criteria. At this stage studies that clearly did not measure people's attitudes, trust, acceptance, or anxiety toward social robots were excluded. For example, technical papers detailing the development of sensors for social robots were removed. Literature reviews, meta-analyses, editorials, newspaper articles, and other forms of popular media were also excluded at this stage as we were only interested in original empirical studies.

Second, the full-text of the identified papers were considered. Where the full-text was not available, the authors of the paper were contacted or the articles were obtained via an interlibrary loan request. Since our research questions focused on social robots exclusively, we used a pre-specified definition checklist (see Supplementary Materials 2) in order to decide whether an article was relevant or not. For example, papers investigating attitudes toward industrial robots were not included unless they also measured attitudes toward social robots. No limitations were placed on the design of the primary studies and studies with randomised and non- 
Fig. 1 PRISMA diagram showing the flow of studies through the review

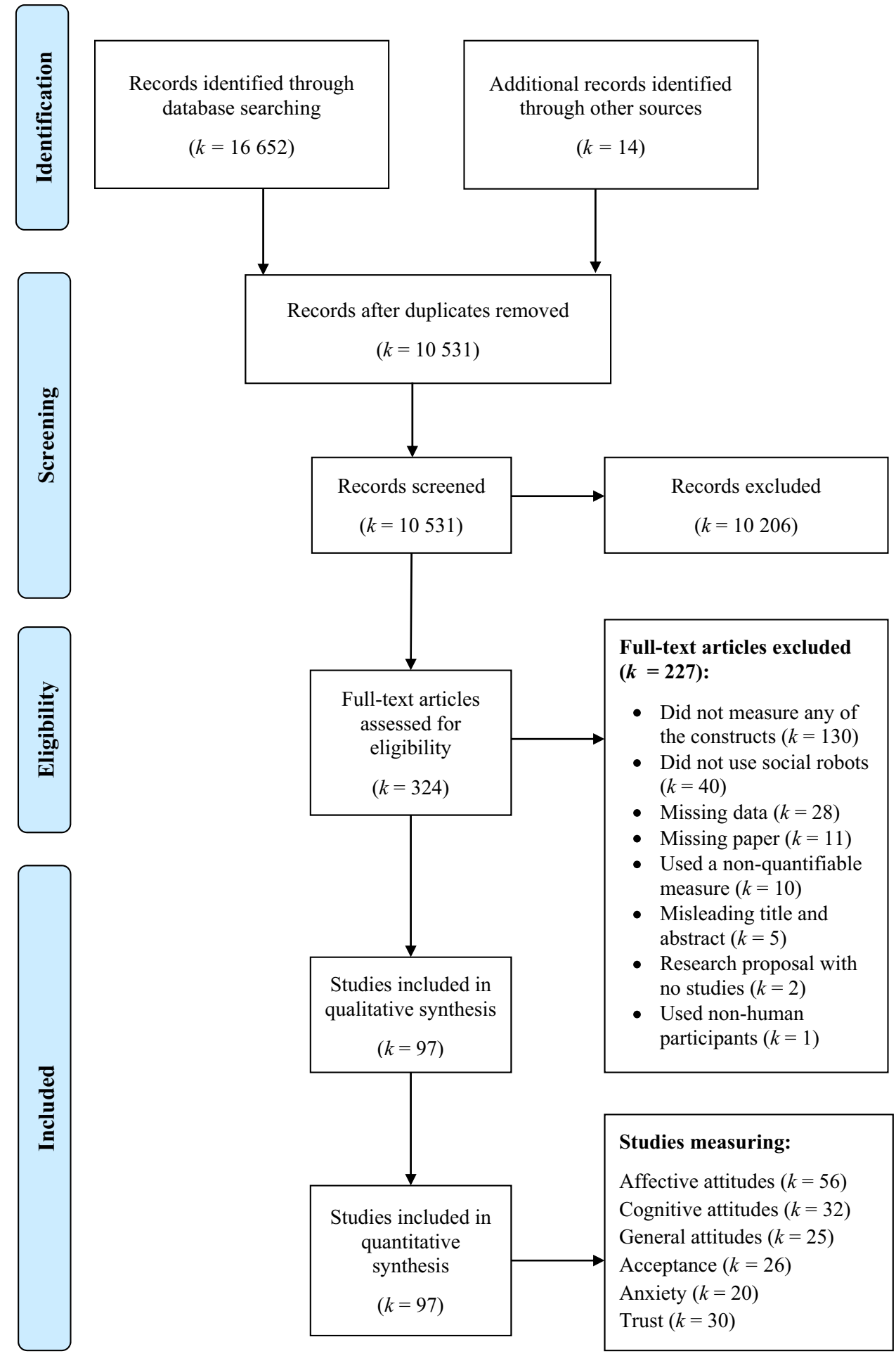

\subsection{Data Extraction}

The information from the primary studies was extracted by a member of the research team and $10 \%$ of the papers were second-coded by a different member of the team, with a comparison showing that $93 \%$ inter-rater agreement was 
reached. Any disagreements or inconsistencies between the two coders were resolved through discussion.

We first extracted bibliographic information from the articles, this included the date of publication, the country where the research was conducted, the sample size and demographics of the sample (i.e., mean age, gender, and cultural or ethnic background), the domain of application, the design of the study, and the name, design, and capabilities of the social robot. The type of outcome (categorised as general attitudes, affective attitudes, cognitive attitudes, behavioural attitudes, trust, anxiety, or acceptance) and details of the measures used to assess each outcome (e.g., the NARS) were identified and extracted next. ${ }^{2}$

The methodological quality of the primary studies (i.e., risk of bias) was assessed using the tool described in Supplementary Materials 3. As with the other characteristics, a member of the research team carried out the quality assessment and a different member of the team second-coded $10 \%$ of the studies. There was moderate inter-rater agreement between the two coders, Cohen's $k=.554,95 \%$ CI [0.43, $0.68], p<.001$. The average difference in the quality scores between the two coders was 0.20 points $(S D=0.18)$ for the overall methodological quality and 0.40 points $(S D=0.16)$ for the separate criteria with a maximum possible difference of 3 points. As before, disagreements were resolved via discussion.

\subsection{Calculating and Interpreting Rescaled and "Standardised" Outcomes}

The present review sought to quantify the valence of people's attitudes toward robots and compare this between different contexts, methods, and samples. As such, traditional effect size metrics used in meta-analyses (i.e., $r$ and $d$ ) were not appropriate for answering our primary research question. We therefore needed a way to estimate the extent to which studies provided evidence that people have positive, neutral, or negative attitudes toward social robots. This was achieved by comparing the average value on the measure of attitude across the sample with the value of the same measure that would reflect a 'neutral' attitude (i.e., one that was neither positive nor negative). For example, if a participant completed a Likert scale measuring attitudes toward robots on a 1-5 scale, then a score of 3 would indicate that this participant has a neutral attitude toward robots.

In order to perform this normalisation, we calculated a pseudo-standardised sample mean $\left(\bar{x}_{S}\right)$ and standard devia-

\footnotetext{
${ }^{2}$ Measures of acceptance typically overlapped with behavioural attitudes (i.e., reflected people's observable or self-reported behaviours and/or intentions to use robots). Therefore, behavioural attitudes were omitted as an outcome and instead we examined evidence on the acceptance of social robots, which was easier to identify.
}

tion $\left(s_{s}\right)$ for each study. To calculate the pseudo-standardised scores, the mean, standard deviation, and the minimum and maximum values of each measure (i.e., scale) were identified, as well as whether the measure indicated a positive or negative outcome (e.g., whether higher values indicated a negative or a positive attitude toward robots). If a measure had multiple subscales (e.g., the NARS), then we sought to extract data separately for each subscale. Missing data was requested from authors via email or via a direct request on ResearchGate. Where the missing data was not obtained within 2 weeks, the papers were excluded. If articles contained multiple measures and the key statistical data was available for at least one of the measures, then the paper was included with the available data. Once all relevant data had been extracted, the following formula was used to calculate the standardised scores where $\bar{x}_{s}$ and $s_{s}$ denote the standardised sample mean and standard deviation and $\bar{x}$ and s denote the sample mean and standard deviation extracted from each study. ${ }^{3}$

$$
\begin{aligned}
& \bar{x}_{s}=\frac{\bar{x}-\mathrm{MR}}{x_{\max }-x_{\min }} \times 2 \\
& s_{s}=\frac{s}{x_{\max }-x_{\min }} \times 2
\end{aligned}
$$

Following this, an average weighted mean $\left(\bar{x}_{w}\right)$ was calculated for each outcome. For studies that had multiple measures or subscales that assessed the same outcome (e.g., affective attitudes), the $\bar{x}_{s}$ and $s_{s}$ for those measures were averaged. As such, each study only contributed a single $\bar{x}_{s}$ and $s_{s}$ for a given outcome (i.e., general attitudes, affective attitudes, cognitive attitudes, behavioural attitudes, trust, anxiety, and/or acceptance). In the following formula, the mean is weighted by $w_{i}$ which denotes the sample size for each study and $\sum w_{i}$ is the sum of all study samples for a particular outcome. We also calculated the variance $\left(s_{\bar{x}_{w}}^{2}\right)$ of each weighted mean where $k$ is the number of studies for each outcome, as well as the $S D\left(s_{\bar{x}_{w}}\right), S E\left(\sigma_{\bar{x}_{w}}\right)$, and $95 \%$ Confidence Intervals where $t_{c}$ is the critical $t$ value for a two-tailed probability at $p<.05$.

$\bar{x}_{w}=\frac{\sum_{i=1}^{n}\left(\bar{x}_{s} \times w_{i}\right)}{\sum_{i=1}^{n} w_{i}}$

$s_{\bar{x}_{w}}^{2}=\frac{\sum_{i=1}^{n}\left(w_{i} \times\left(\bar{x}_{s}-\bar{x}_{w}\right)^{2}\right)}{\frac{\sum_{i=1}^{n} w_{i} \times(k-1)}{k}}$

$s_{\bar{x}_{w}}=\sqrt{s^{2}}$

\footnotetext{
${ }^{3}$ Note that $M R$ is the numerical value for each scale that indicates a neutral attitude. If a scale measured negative attitudes, then $\bar{x}$ was reversed prior to calculating $\bar{x}_{5}$ by adding the maximum $\left(x_{\max }\right)$ and minimum $\left(x_{\min }\right)$ possible values of each scale and taking away the $\bar{x}$ (e.g., for a 1-5 scale with a mean of 2 , the reversed score would be (1 $+5)-2=4$.
} 
$\sigma_{\bar{x}_{w}}=\frac{s}{\sqrt{\frac{\sum w_{i}}{k}}}$

$95 \% C I_{\bar{x}_{w}} \approx\left[\bar{x}_{w} \pm t_{c} \times \sigma\right]$

Taken together, $\bar{x}_{s}$ and $s_{s}$ can be interpreted as a sample mean and standard deviation on a scale of -1 (indicating an extremely negative outcome) to +1 (indicating an extremely positive outcome). Since all possible values of $\bar{x}_{s}$ and $\bar{x}_{w}$ fall within a scale with an absolute maximum and minimum values, we propose that the computed means can be interpreted in a manner that is comparable, but not identical, to that conventionally applied to Pearson's $r$. Specifically, we propose that the midpoint between neutral attitudes and the two extremes of negative and positive attitudes (i.e., $\bar{x} \geq$ \pm 0.50 ) is interpreted as a large-sized (or substantial) positive or negative attitude, $\bar{x} \geq \pm 0.30$ as a medium-sized (or moderate) positive or negative attitude, and $\bar{x} \geq \pm 0.10$ as a small-sized (or slight) positive or negative attitude.

\subsection{Calculating and Interpreting Weighted Means, Standard Error, and 95\% Confidence Intervals}

In order to investigate whether categorical factors (e.g., type of HRI, domain of application, and robot design) are associated with people's attitudes toward social robots, we computed an average weighted mean $\left(\bar{x}_{m}\right)$ for each level of each moderator (e.g., a weighted mean for all studies with no HRI, a weighted mean for all studies with indirect HRI, and a weighted mean for all studies with direct HRI). We excluded any studies where the outcome was measured using two or more different types of exposure to the robot, or for different robots that had different application areas, or where the outcome was measured for different robots that had different designs or no design was specified. Unlike $\bar{x}_{w}$, the $\bar{x}_{m}$ was weighted by the reported sample variance $\left(s_{s}^{2}\right)$ in each study (in other words, we applied inverse-variance weighting instead of frequency weighting). We also calculated the variance $\left(s_{\bar{x}_{m}}^{2}\right)$ of each weighted mean, as well as the $S D\left(s_{\bar{x}_{m}}\right), S E$ $\left(\sigma_{\bar{x}_{w}}\right)$, and $95 \%$ Confidence Intervals where $t_{c}$ is the critical $t$ value for a two-tailed probability at $p<.05$.

$$
\begin{array}{rl}
\bar{x}_{m} & =\frac{\sum_{i=1}^{n}\left(x_{s} / s_{s}^{2}\right)}{\sum_{i=1}^{n}\left(1 / s_{s}^{2}\right)} \\
s_{\bar{x}_{m}}^{2} & =\frac{1}{\sum_{i=1}^{n}\left(1 / s_{s}^{2}\right)} \\
s_{\bar{x}_{m}} & =\sqrt{s^{2}} \\
\sigma_{\bar{x}_{m}} & =\frac{s}{\sqrt{k}} \\
95 \% & C I_{\bar{x}_{m}} \approx\left[\bar{x}_{m} \pm t_{c} \times \sigma\right]
\end{array}
$$

Table 1 reports the weighed means, standard deviations, and $95 \%$ CIs for each level of each moderator. Larger positive and negative values of $\bar{x}_{m}$ indicate a more positive or negative outcome respectively. An overlap between confidence intervals indicates that there is insufficient evidence to conclude that there is a difference in the outcomes between the groups as a function of a given factor. Conversely, no overlap between the confidence intervals indicates that there is a difference in the outcomes between the groups as a function of a particular factor.

\section{Results}

\subsection{Description of Included Studies}

Data on people's acceptance of, attitudes toward, anxiety associated with, and trust in social robots was obtained from $k=97$ studies published between 2005 and early 2019 in scientific journals $(52 \%)$ or in conference proceedings $(45 \%)$, with only three studies coming from alternative sources. The majority of these studies were conducted in the USA (17\%), Germany (13\%), and Japan (11\%). The average size of the sample in the included studies was $N=135(S D=182)$ and the majority of studies (68\%) were published between 2014 and 2019.

\subsection{Affective Attitudes}

Attitudes toward social robots were most commonly assessed in terms of affective attitudes, with the majority of studies $(k=56,58 \%)$ including at least one measure of affective attitudes (i.e., feelings or emotions toward social robots). Not surprisingly, given the popularity of the Negative Attitudes towards Robots Scale (NARS; [10]) in HRI research, seventeen studies $(30 \%)$ used the full scale or subscales to measure participants' affective attitudes. We categorised both the NARS-S1 (interaction with robots) and NARS-S3 (emotions in interaction with robots) subscales as measures of affective attitudes, as the items enquire how people expect to feel when they interact with social robots. Other measures of affective attitudes included other validated scales (e.g., Godspeed Questionnaire Series_-likability) and less-known self-report measures (e.g., semantic differential scales based on [56]). Twelve studies (21\%) measured participants' affective attitudes toward social robots in general (e.g., [57]) or specific types of social robots (e.g., domestic robots; [37]), while the rest measured participants' attitudes toward specific social robots (e.g., NAO; [43]).

The average weighted mean for affective attitudes was $\bar{x}_{w}$ $=0.27$ (see Fig. 2), suggesting that people generally have slight (bordering on moderate) positive affective attitudes toward social robots. Eight studies (14\%) found evidence 


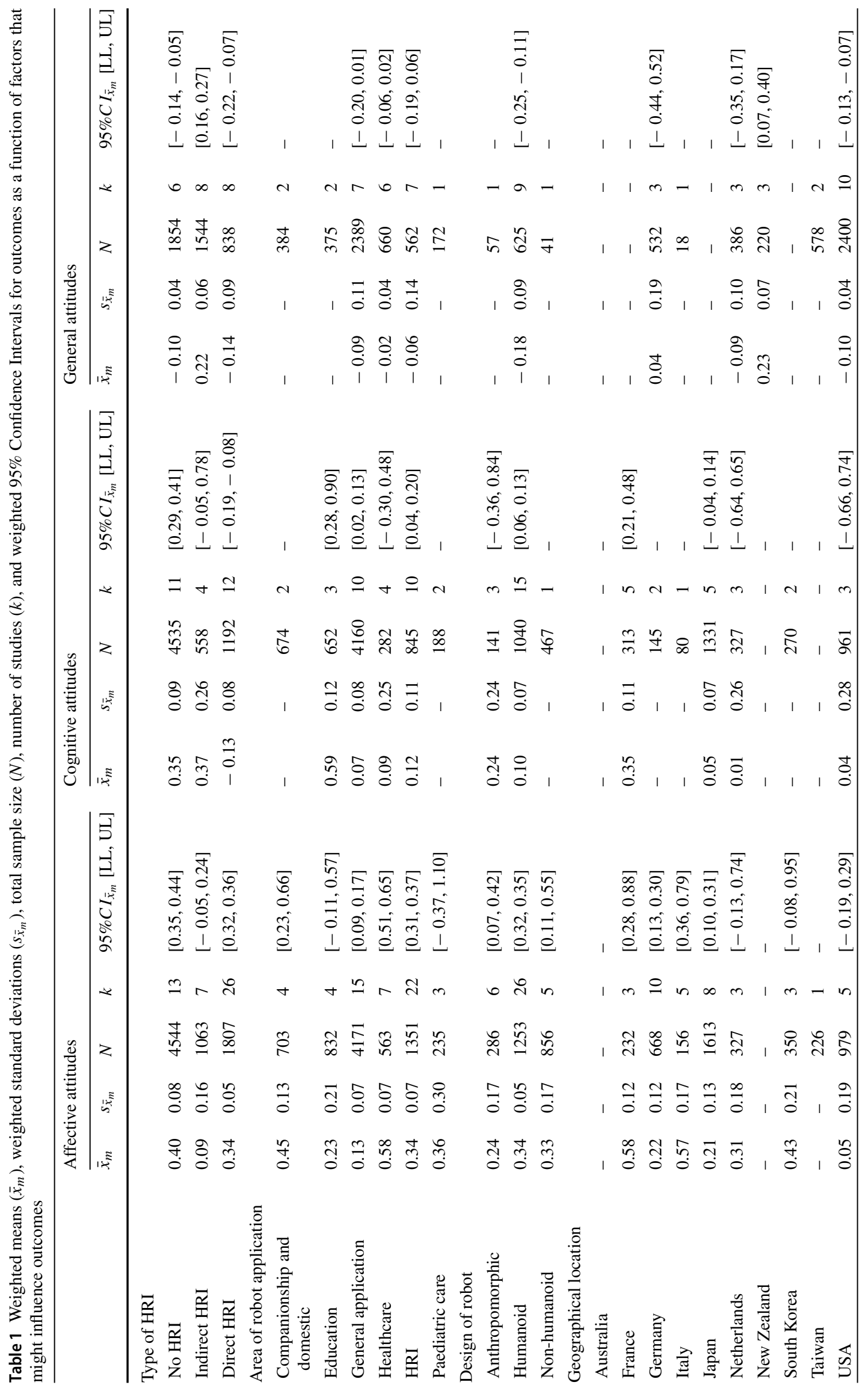




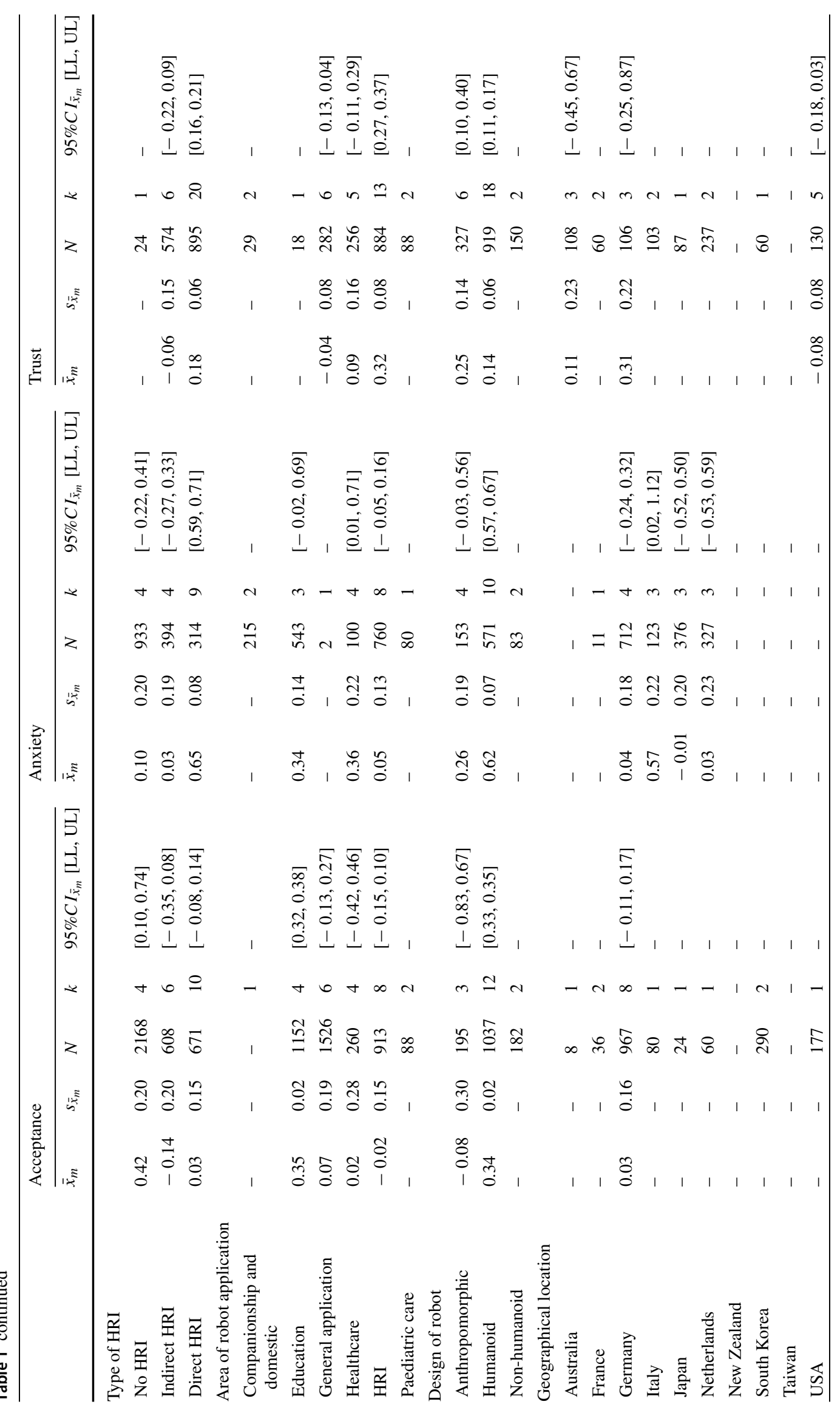


that people held negative affective attitudes toward social robots (i.e., $\left.\bar{x}_{w}<0\right)$ and only 16 studies $(29 \%)$ had a mean of $\bar{x}_{s}> \pm 0.50$, signifying that people held substantially positive or negative affective attitudes.

\subsection{Cognitive Attitudes}

Thirty-two studies (33\%) included at least one measure of cognitive attitudes (i.e., people's cognitive evaluations or thoughts about social robots). The NARS, or more specifically the NARS-S2 subscale (reflecting beliefs about the social influence of robots), was the most commonly used measure $(k=17,53 \%)$. Subscales of questionnaires relating to specific models such as the Almere Model of robot acceptance [15] and Unified Theory of Acceptance and Use of Technology (UTAUT; [33]) were also used to measure cognitive attitudes [58-60].

The average weighted mean for cognitive attitudes was $\bar{x}_{w}=0.24$, indicating that, in general, people had slightly positive cognitive evaluations about social robots and their use (see Fig. 3). The majority of studies $(72 \%)$ found evidence for positive cognitive attitudes with one study, [61], providing evidence for neutral cognitive attitudes $\left(\bar{x}_{s} \approx 0\right)$.

\subsection{General Attitudes}

Twenty-five studies (26\%) measured attitudes toward social robots in a general way-i.e., overall evaluations of the extent to which social robots are 'good' or 'bad' and/or measures that combined affective and cognitive evaluations. General attitudes were almost exclusively measured via self-report with the exception of three studies (12\%) that used the Implicit Association Test (IAT). The aggregated data (see Fig. 4) indicated an average weighted mean of $\bar{x}_{w}=0.07$, which suggests that people's general attitudes toward social robots tended to be neutral (bordering on slightly positive). Thirteen studies $(55 \%)$ provided evidence of positive general attitudes (i.e., $\bar{x}_{w}>0$ ) toward social robots while the rest provided evidence for negative attitudes, with one study reporting neutral attitudes (i.e., $\bar{x}_{w}=0$ ).

\subsection{Acceptance}

Twenty-six of the included studies (27\%) measured acceptance in terms of people's intentions to use social robots, actual use of specific social robots or social robots in general, or people's willingness to interact with social robots. The average weighted mean for this outcome $\left(\bar{x}_{w}=0.24\right)$ indicated that, in general, people accept social robots but only slightly so. However, acceptance of social robots varied considerably (see Fig. 5) and $42 \%$ of studies suggested that people did not accept robots (i.e., $\bar{x}_{w}<0$ ).

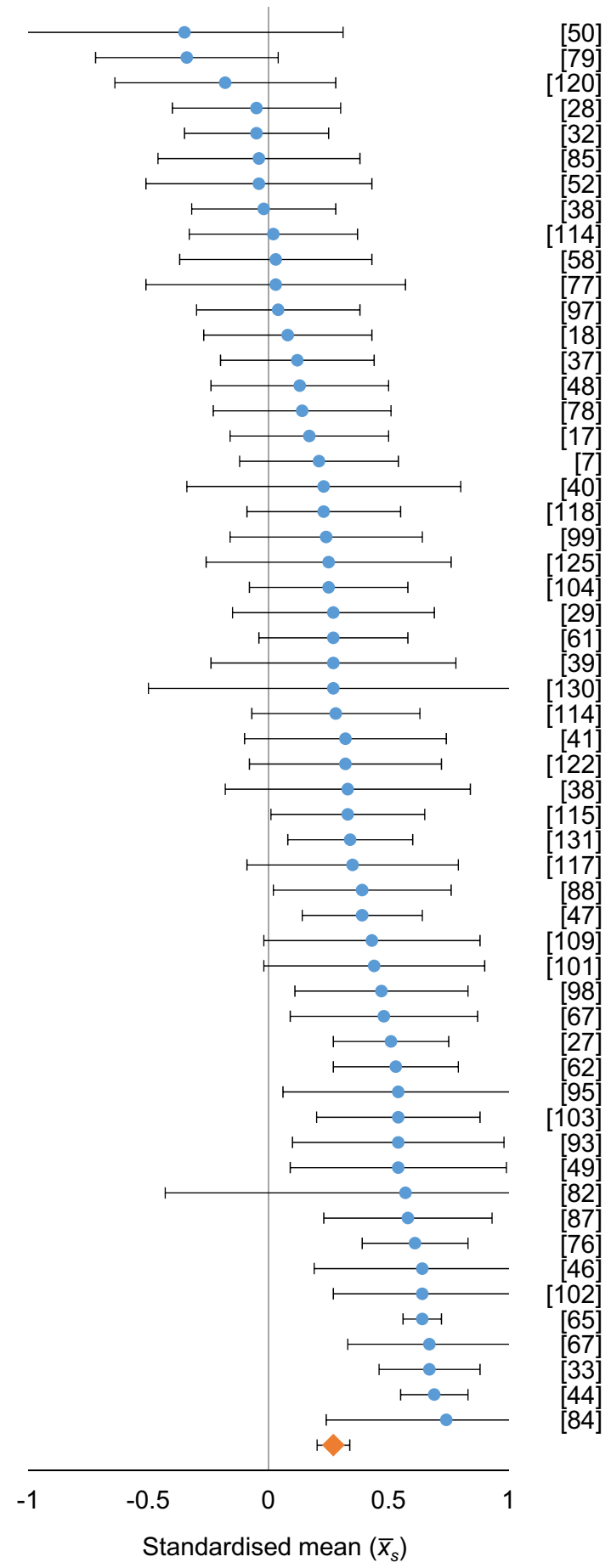

Fig. 2 Plot of pseudo-standardised means $\left(\bar{x}_{s}\right)$ for studies measuring affective attitudes toward social robots. Error bars of the blue data points represent the standard deviation $\left(s_{s}\right)$ of the mean. The orange data point represents the average weighted mean $\left(\bar{x}_{w}\right)$ for affective attitudes and the error bars represent $95 \% C I_{\bar{x}_{w}}$

Two studies in particular should be mentioned as they are rather atypical as compared to the other studies measuring acceptance. First, Fridin and Belokopytov [62] reported an unusually small standard deviation $\left(s_{s}\right)$ indicating very little 


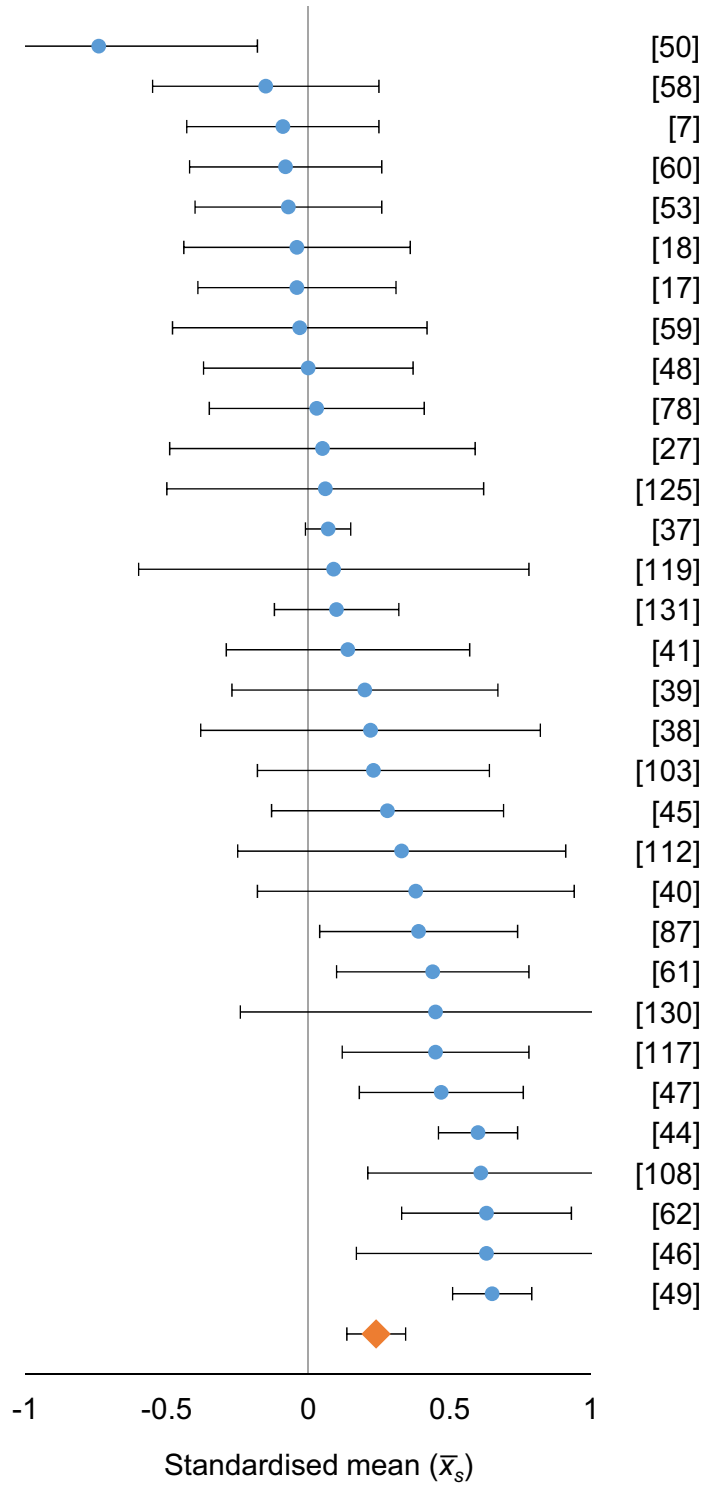

Fig. 3 Plot of pseudo-standardised means $\left(\bar{x}_{s}\right)$ for studies measuring cognitive attitudes toward social robots. Error bars of the blue data points represent the standard deviation $\left(\mathrm{s}_{\mathrm{s}}\right)$ of the mean. The orange data point represents the average weighted mean $\left(\bar{x}_{w}\right)$ for cognitive attitudes and the error bars represent $95 \% C I_{\bar{x}_{w}}$

variation in participants' acceptance of social robots. This may be explained by the specific conditions and sample in this study. Participants were all preschool and elementary school teachers that attended a professional workshop on educational robotics where they were introduced to the capabilities of a NAO robot. This may explain why participants' views on robots aligned quite well. Second, Wu et al. [63] found strong evidence that participants did not accept robots $\left(\bar{x}_{w}=-0.99\right)$ These negative beliefs may be explained by the finding that the participants who interacted with a social robot for a month in a Living Lab setting did not find the robot useful. Perceived usefulness has previously been iden-

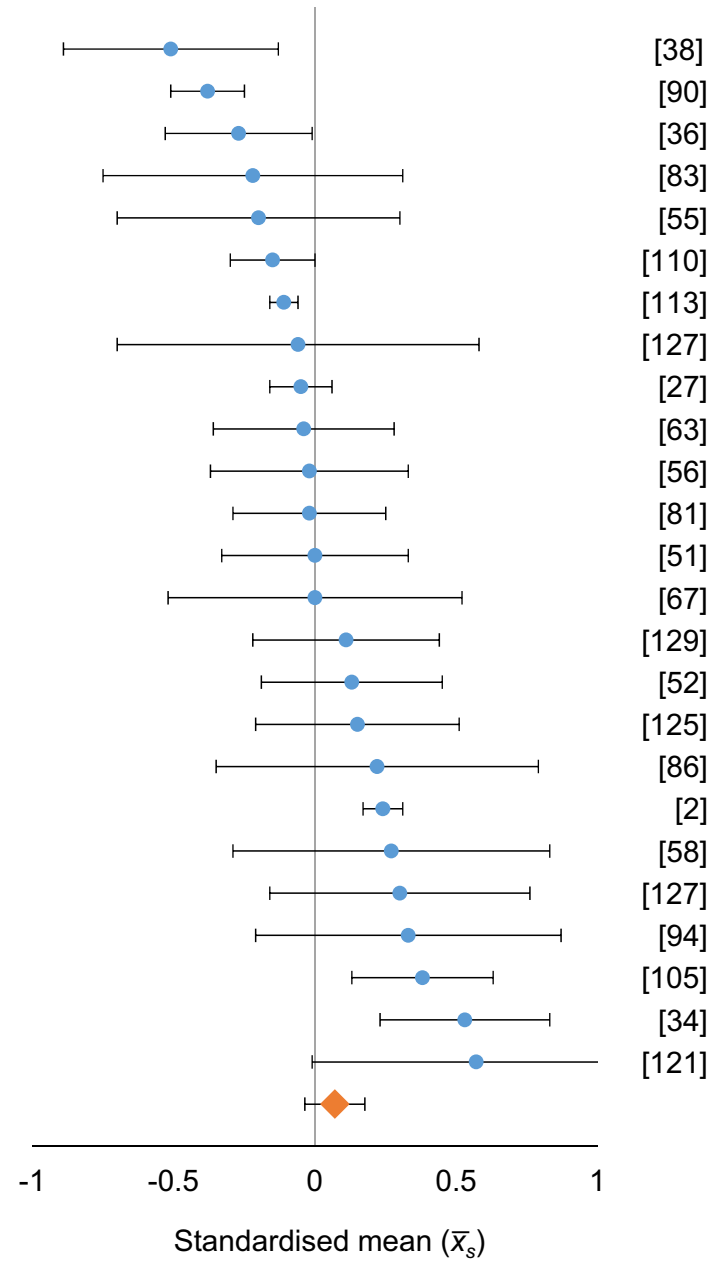

Fig. 4 Plot of pseudo-standardised means $\left(\bar{x}_{s}\right)$ for studies measuring general attitudes toward social robots. Error bars of the blue data points represent the standard deviation $\left(s_{s}\right)$ of the mean. The orange data point represents the average weighted mean $\left(\bar{x}_{w}\right)$ for general attitudes and the error bars represent $95 \% C I_{\bar{x}_{w}}$

tified as a factor that impacts participants' intention to use robots [33].

\subsection{Anxiety}

Twenty studies (21\%) measured people's feelings of anxiety or nervousness evoked by social robots. Anxiety was predominantly assessed via the Robot Anxiety Scale (RAS; [25]) with ten studies (50\%) having used some variation of the measure $[37,64,65]$. Other commonly used measures $(k=5,25 \%)$ were the subscales of adapted questionnaires relating to specific models such as the Almere Model of robot acceptance [15] and Unified Theory of Acceptance and Use of Technology (UTAUT; [33]). All of the studies used self-report measures of anxiety with some studies measuring either anxiety toward specific social robots or toward social robots in general. 


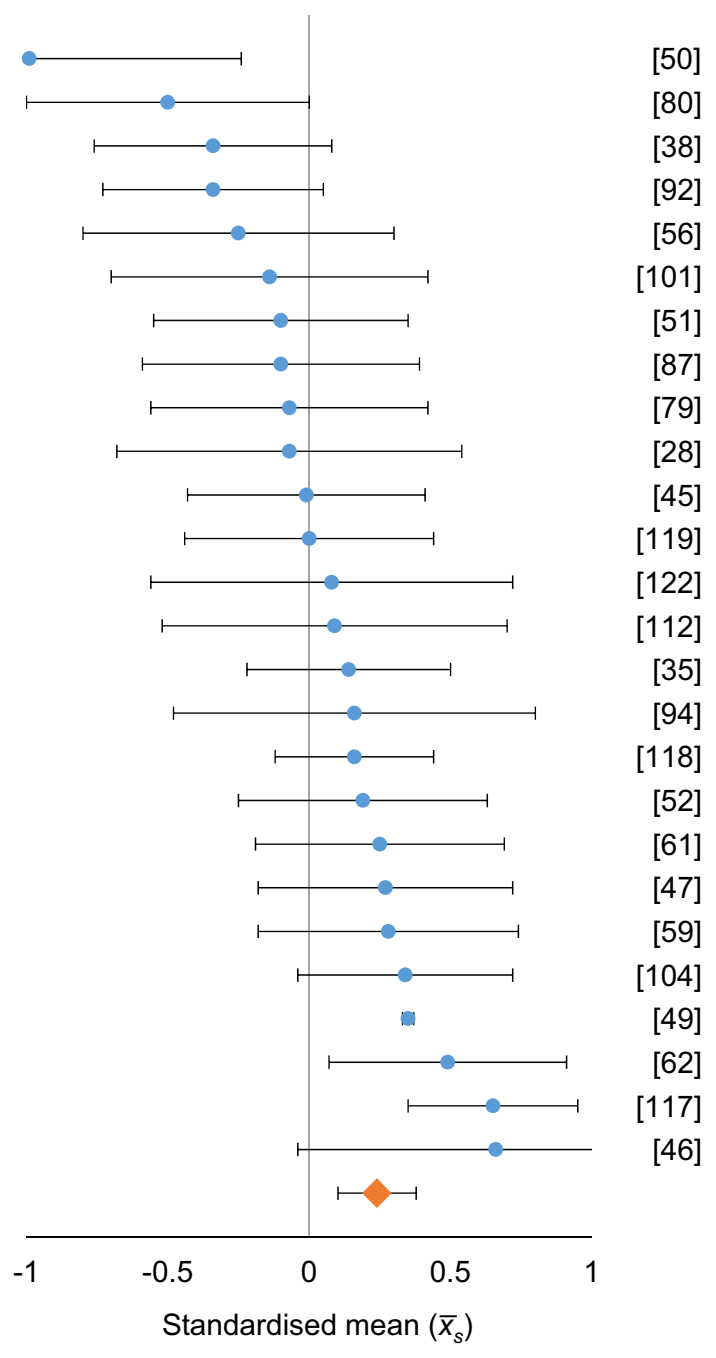

Fig. 5 Plot of pseudo-standardised means $\left(\bar{x}_{S}\right)$ for studies measuring acceptance toward social robots. Positive values represent greater acceptance. Error bars of the blue data points represent the standard deviation $\left(s_{s}\right)$ of the mean. The orange data point represents the average weighted mean $\left(\bar{x}_{w}\right)$ for acceptance and the error bars represent $95 \% C I_{\bar{x}_{w}}$

We found an average weighted mean of $\bar{x}_{w}=0.10$ for anxiety, indicating that, in general, people only feel slightly anxious about social robots. Indeed, the majority of studies $(k=9,45 \%)$ found that participants' levels of anxiety were fairly neutral (i.e., $\bar{x}_{w}< \pm 0.10$, see Fig. 6). The $95 \% C I_{\bar{x}_{w}}$ further support this conclusion with confidence limits that cross 0 but do not exceed $\bar{x}_{w}=-0.10$ (see Fig. 6).

\subsection{Trust}

Thirty studies (31\%) measured trust in social robots. Unlike the other outcomes, measures of trust were notably more varied and included behavioural $[17,66]$ as well as selfreport measures. However, trust was typically assessed via subscales of adapted questionnaires relating to specific mod-

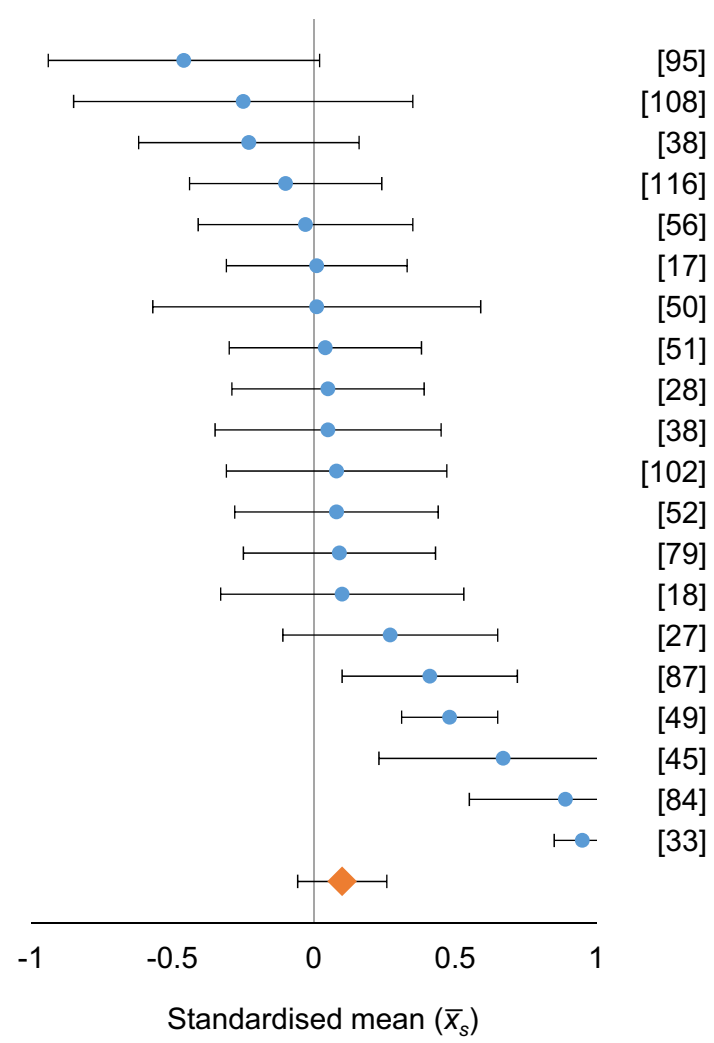

Fig. 6 Plot of pseudo-standardised means $\left(\bar{x}_{s}\right)$ for studies measuring anxiety toward social robots. Positive values represent lesser anxiety. Error bars of the blue data points represent the standard deviation $\left(s_{S}\right)$ of the mean. The orange data point represents the average weighted mean $\left(\bar{x}_{w}\right)$ for anxiety and the error bars represent $95 \% C I_{\bar{x}_{w}}$

els such as the Almere Model of robot acceptance [15] and the Unified Theory of Acceptance and Use of Technology [33].

The average weighted mean for trust was close to zero, $\bar{x}_{w}=0.06$, suggesting that, in general, people did not particularly trust or distrust social robots. However, the plot of all included studies (see Fig. 7) indicated variation within and between studies with $43 \%$ of studies presenting evidence that people did not trust social robots (i.e., $\bar{x}_{w}<0$ ).

\subsection{Factors that Influence the Main Outcomes}

Table 1 shows the weighted means $\left(\bar{x}_{m}\right)$ and confidence intervals $\left(95 \% C I_{\bar{x}_{m}}\right)$ for each outcome as a function of factors that might influence that outcome (e.g., the nature of the social robot). In addition, the findings have been illustrated graphically in Supplementary Materials 1.

\subsubsection{Type of Exposure to Robots}

We compared attitudes in studies that included three different types of human-robot interaction: no HRI, an indirect 


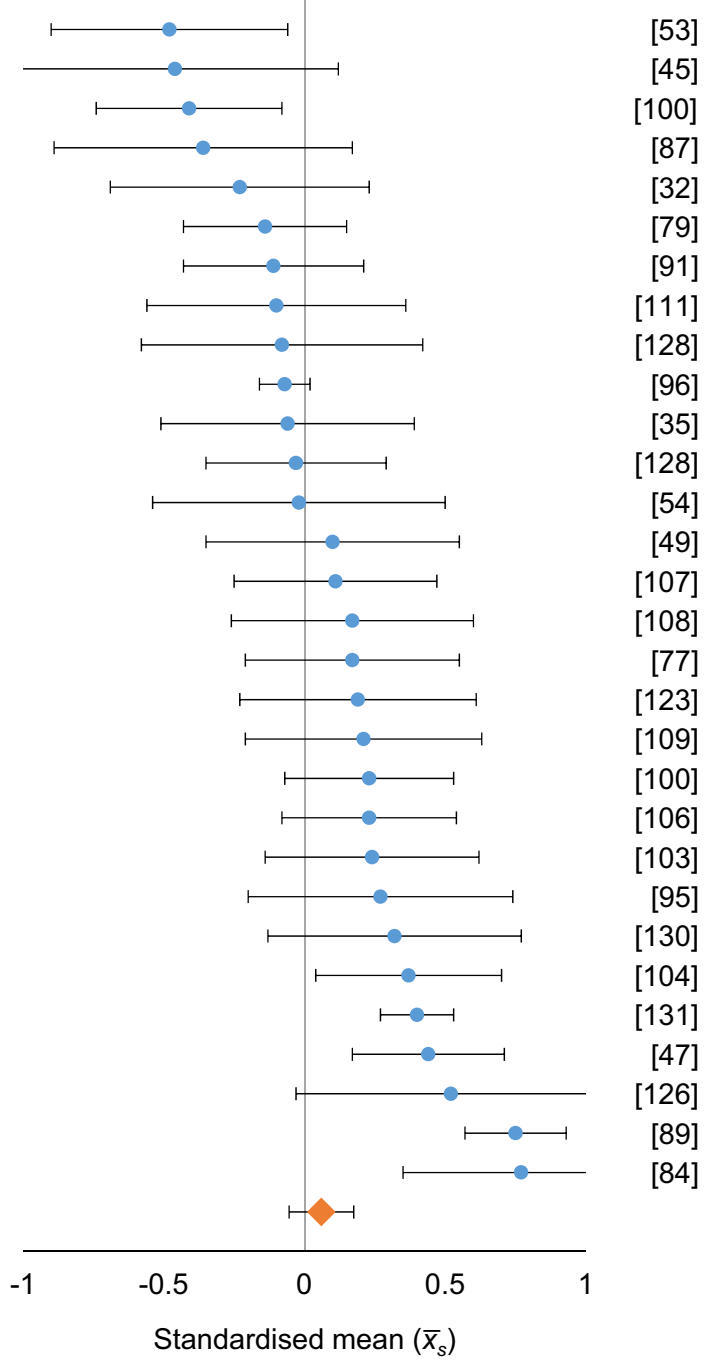

Fig. 7 Plot of pseudo-standardised means $\left(\bar{x}_{s}\right)$ for studies measuring trust toward social robots. Positive values represent greater trust. Error bars of the blue data points represent the standard deviation $\left(s_{s}\right)$ of the mean. The orange data point represents the average weighted mean $\left(\bar{x}_{w}\right)$ for trust and the error bars represent $95 \% C I_{\bar{x}_{w}}$

form of HRI, and direct HRI. For studies measuring affective attitudes, the average weighted mean for studies that did not include any type of HRI was larger $\left(\bar{x}_{m}=0.40\right)$ than for studies where indirect contact $\left(\bar{x}_{m}=0.09\right)$ with social robots was included. We also found more positive affective attitudes toward social robots for studies that included direct HRI $\left(\bar{x}_{m}\right.$ $=0.34)$ as compared to indirect HRI $\left(\bar{x}_{m}=0.09\right)$. There was no evidence that affective attitudes differed between no HRI and direct HRI $\left(\bar{x}_{m}=0.34\right)$. This suggests that, in general, when people are asked about their feelings toward social robots, they report more positive affective attitudes when they either do not interact with a social robot at all or directly interact with it, rather than when they experience some type of indirect contact.
For cognitive attitudes, there was no overlap between the 95\% $C I_{\bar{x}_{m}}$ for no HRI and direct HRI, indicating that participants thoughts about social robots were more positive in studies where there was no interaction between participants and robots $\left(\bar{x}_{m}=0.35\right)$ than when there was direct interaction $\left(\bar{x}_{m}=-0.13\right)$. There was no evidence that cognitive attitudes differed between studies that involved indirect HRI $\left(\bar{x}_{m}=0.37\right)$ and no HRI.

With respect to general attitudes, participants appeared to report more positive attitudes toward social robots in studies with indirect forms of HRI $\left(\bar{x}_{m}=0.22\right)$ than in studies with direct $\left(\bar{x}_{m}=-0.14\right)$ or no HRI $\left(\bar{x}_{m}=-0.10\right)$. This lack of overlap between the $95 \% C I_{\bar{x}_{m}}$ suggests that participants attitudes toward social robots tend to be more positive when they interact with the robots indirectly (e.g., by watching a video; [67]) rather than when they interact directly or do not interact with a social robot at all.

There was no overlap between confidence intervals for acceptance of social robots between studies where there was no HRI $\left(\bar{x}_{m}=0.42\right)$ and for studies with indirect HRI $\left(\bar{x}_{m}=\right.$ $-0.14)$, suggesting that, in general, people are more accepting of social robots with which they have had no contact as compared to robots they have interacted with indirectly.

For anxiety, there was no overlap between confidence intervals for studies that included direct and indirect HRI. This indicates that, in general, participants reported considerably less anxiety when directly interacting with social robots $\left(\bar{x}_{m}=0.65\right)$ than when taking part in indirect HRI $\left(\bar{x}_{m}=\right.$ $0.03)$ or no HRI $\left(\bar{x}_{m}=0.10\right)$.

Results from the studies measuring trust were consistent with the findings for anxiety. In general, for studies where there was direct HRI, participants exhibited or reported more trust in social robots $\left(\bar{x}_{m}=0.18\right)$ than participants in studies where the contact with the social robots was indirect $\left(\bar{x}_{m}=\right.$ -0.06 ). Unfortunately, too few studies measured trust in the absence of HRI so we were unable to compare this group to indirect and direct HRI.

In addition to considering whether the type of exposure to robots provided in experimental studies influences people's beliefs about robots, we also sought to examine the effects of long-term exposure to robots by comparing attitudes and beliefs in studies where the majority (i.e., over half) of the participants indicated that they had seen or interacted with robots with studies where more than half of the participants had not previously seen or interacted with robots. Although fourteen studies reported the number of participants that had seen or interacted with social robots previously, in all but one of those studies the majority of participants had no previous experience with robots. Therefore, it was not possible to examine the effect of long-term interactions on beliefs about social robots in this review. 


\subsubsection{Domain of Application}

We looked at attitudes toward robots in six different domains of application: (1) companionship and domestic use, (2) education, (3) general application, (4) healthcare, (5) HRI, and (6) paediatric care.

We found three main differences, indicated by no overlap between confidence intervals, for studies measuring affective attitudes. In general, participants' affective attitudes toward social robots intended for companionship or domestic purposes were more positive $\left(\bar{x}_{m}=0.45\right)$ than were participants' attitudes toward social robots intended to have a general application $\left(\bar{x}_{m}=0.13\right)$. In addition, participants had more positive affective attitudes toward social robots in healthcare settings $\left(\bar{x}_{m}=0.58\right)$ than robots with a general or HRIfocused application $\left(\bar{x}_{m}=0.13\right.$ and 0.34 , respectively).

Participants reported more positive cognitive attitudes toward social robots in educational domains $\left(\bar{x}_{m}=0.59\right)$ than did participants where the social robot had a general $\left(\bar{x}_{m}=0.07\right)$ or HRI-focused $\left(\bar{x}_{m}=0.12\right)$ application. There were no other differences of note.

No differences in general attitudes were found as a function of the domain of application as the confidence intervals for all groups overlapped. However, it should be noted that we could only identify enough studies to compare general attitudes toward social robots in three domains of application-healthcare, general application, and HRI.

With respect to acceptance, participants seemed more accepting of social robots in educational domains $\left(\bar{x}_{m}=0.35\right)$ than social robots with a general, healthcare, or HRI-focused application $\left(\bar{x}_{m}=0.07,0.02\right.$, and -0.02 , respectively).

We were only able to compare three different domains of application for studies measuring anxiety and found no evidence of differences in anxiety associated with social robots as a function of their domain of application.

Finally, we compared trust associated with social robots in three domains of application. There was a difference in trust between studies where the social robot had a healthcare application and studies where the social robot had an HRI-focused application as indicated by no overlap between the confidence intervals for those two groups. Participants reported less trust in social robots intended for healthcare settings $\left(\bar{x}_{m}=0.09\right)$ and for general application $\left(\bar{x}_{m}=-\right.$ $0.04)$, than in social robots intended for HRI $\left(\bar{x}_{m}=0.32\right)$.

\subsubsection{Design of Robot}

We looked at differences between three broad categories of social robots' design: anthropomorphic, humanoid, and nonhumanoid robots. Unfortunately, for all six outcomes, the majority of studies focused exclusively on participants' attitudes toward humanoid social robots (see Table 1). As such, there was insufficient evidence on people's beliefs about anthropomorphic and non-humanoid social robots, resulting in fairly large confidence intervals that made comparisons difficult. Consequently, we were either unable to compare the three design groups or found no evidence of differences in affective attitudes, cognitive attitudes, acceptance, anxiety, general attitudes, or trust as a function of the design of the social robot.

\subsubsection{Geographical Location}

We sought to compare attitudes between eight geographical locations in which the data collection took place: Australia, France, Germany, Italy, Japan, Netherlands, New Zealand, South Korea, Taiwan, and the USA (see Table 1).

We found three main differences, indicated by no overlap between confidence intervals, for studies measuring affective attitudes. In general, estimates of participants' affective attitudes toward social robots from studies conducted in Italy $\left(\bar{x}_{m}=0.57\right)$ were more positive than were participants' attitudes from studies conducted in Germany $\left(\bar{x}_{m}=0.22\right)$, Japan $\left(\bar{x}_{m}=0.21\right)$, and the USA $\left(\bar{x}_{m}=0.05\right)$.

Participants from studies conducted in France $\left(\bar{x}_{m}=0.35\right)$ reported more positive cognitive beliefs about social robots than did participants who took part in studies conducted in Japan $\left(\bar{x}_{m}=0.05\right)$. No other differences between people's cognitive attitudes were found, although it should be noted that due to a limited number of studies we were only able to compare four of the eight eligible geographical locations.

We were only able to compare people's general attitudes from studies conducted in Germany, the Netherlands, New Zealand, and the USA. We found that participants' general attitudes toward social robots from studies conducted in New Zealand $\left(\bar{x}_{m}=0.23\right)$ tended to be more positive than those of studies conducted in the USA $\left(\bar{x}_{m}=-0.10\right)$.

We were unable to compare acceptance between the countries as Germany was the only geographical location for which we had enough data to calculate $\bar{x}_{m}$.

We found no differences in the levels of anxiety people experience toward social robots as a function of the location at which the study was conducted. However, we were only able to compare studies conducted in Germany, Italy, Japan, and the Netherlands, and on average we were only able to include three studies per location resulting in large 95\% CIs that made comparisons difficult.

Similarly, we found no differences in people's level of trust in social robots as a function of the location at which the study was conducted and we were only able to compare studies conducted in Australia, Italy, and the USA.

\subsubsection{Age of Participants}

In order to investigate whether participants' age was associated with their beliefs about social robots, we conducted 
a weighted least squares regression with the average age of participants in each study as the independent variable, the sample mean $\left(\bar{x}_{s}\right)$ as the dependant variable, and the size of the sample in each study as the weight. A Bonferroni correction was applied to account for the multiple comparisons and an adjusted critical $p$ value of .008 was used. These analyses indicated that the age of the participants was not significantly associated with their affective attitudes toward social robots, $F(1,43)=1.90, p=.176$, cognitive attitudes toward social robots, $F(1,22)=1.90, p=.182$, general attitudes, $F(1,22)$ $=0.00, p=.948$, acceptance, $F(1,21)=3.80, p=.065$, anxiety, $F(1,16)=0.00, p=.981$, or trust, $F(1,20)=1.35$, $p=.259$.

\subsubsection{Gender of Participants}

In order to investigate whether gender was associated with participants' beliefs about social robots, we conducted a weighted least squares regression with the percentage of female participants in each study as the independent variable, the sample mean $\left(\bar{x}_{s}\right)$ as the dependant variable, and the size of the sample in each study as the weights. A Bonferroni correction was applied to account for the multiple comparisons and an adjusted critical $p$ value of .008 was used. The percentage of female participants accounted for $40.9 \%$ of the variation in self-reported trust in social robots, $R^{2}=.64, F(1,19)=13.16, p=.002$, such that there was a strong positive linear relationship between the two. However, the gender of the participants was not associated with their affective attitudes toward social robots, $F(1,45)=1.98, p=$ .166 , cognitive attitudes, $F(1,24)=0.04, p=.853$, general attitudes, $F(1,20)=4.28, p=.052$, acceptance, $F(1,20)=$ $5.70, p=.658$, or anxiety, $F(1,13)=5.89, p=.031$.

\subsubsection{Year of Publication}

In order to investigate whether beliefs about social robots have changed over time, we conducted a weighted least squares regression for each of the six outcomes with the year in which the study was published as the independent variable, the sample mean $\left(\bar{x}_{S}\right)$ as the dependant variable, and the sample size of each study as the weight. The average number of studies published each year prior to 2014 was quite small ( $M$ $=3.44$ ) and therefore the findings of the linear regressions should be interpreted with caution. The year of publication was not associated with affective attitudes, $F(1,55)=0.17$, $p=.684$; cognitive attitudes, $F(1,31)=0.49, p=.489$; general attitudes, $F(1,23)=3.00, p=.096$; acceptance, $F(1$, $23)=0.32, p=.575$; anxiety, $F(1,18)=0.03, p=.856$; or trust, $F(1,28)=0.001, p=.986$.

\subsubsection{Methodological Quality}

The average overall methodological quality of the included studies was $2.20(S D=0.50$, range $=1.30-3.30)$ on a scale from 1 (poor quality) to 4 (excellent quality) (see Supplementary Materials 3). It should be noted that most studies received a quality score close to the average, indicating little variation in the overall methodological quality as measured via our Quality Assessment Tool. However, a number of individual criterion may have contributed to this homogeneity. Most notably, the Objectivity criterion $(M=2.00, S D=$ 0.20 ) as the majority of studies ( $94 \%)$ measured our main outcomes using some form of questionnaire or scale which we rated as lower than behavioural and physiological measures. Similarly, the Reliability (a) criterion $(M=1.30, S D=$ 0.60 ) indicated that the majority of studies did not measure test-retest reliability, thus resulting in a score of 1 for the majority of studies (70\%). Scores for the External Validity (b) criterion were similarly homogeneous $(M=1.40, S D=$ 0.60 ) as most studies did not employ a randomised sampling technique. By far the most common type of sample used by $30 \%$ of the studies consisted of University students recruited on a volunteer basis.

In order to investigate whether the methodological quality of studies was associated with participants' beliefs about social robots, we conducted a Linear Regression with the methodological quality scores of each study as the independent variable, and the sample mean $\left(\bar{x}_{S}\right)$ as the dependant variable. A Bonferroni correction was applied to account for the multiple comparisons and an adjusted critical $p$ value of .008 was used. The methodological score given to the included studies was not associated with participants' affective attitudes toward robots, $F(1,54)=1.25, p=.269$; cognitive attitudes, $F(1,30)=0.02, p=.878$; general attitudes, $F(1,23)=2.39, p=.136$; acceptance of robots, $F(1$, $24)=1.33, p=.260$; anxiety toward robots, $F(1,18)=1.19$, $p=.056$; and trust in robots, $F(1,31)=0.37, p=.549$.

\section{Discussion}

The present review quantified and synthesised evidence on people's beliefs about social robots. Although reviews have been conducted in this area $[31,34,41,55]$, none have combined the various measures employed in primary studies in a way that informs the overall valence (i.e., positive, neutral, or negative) and magnitude of the outcomes. The approach described in this paper is, to our knowledge, the first of its kind to provide standardised estimates of the overall valence of people's attitudes toward robots and related beliefs based on evidence from multiple studies and measures. 


\subsection{What are People's Attitudes Toward Social Robots?}

The majority of studies that measured people's affective attitudes suggested that people have slightly positive (bordering on moderate) feelings about social robots. We consider this finding to be fairly robust as only nine studies provided evidence that people have negative feelings toward social robots. Upon further examination of these nine studies, two had somewhat atypical methodologies—one study employed imagined contact with robots [64] and the other tested whether involving users in the development of robots affected their attitudes [68].

Studies measuring cognitive attitudes provided further support for overall positive attitudes toward robots with a sample-weighted mean similar in magnitude to that found for affective attitudes. This similarity between affective and cognitive attitudes is consistent with models in psychology that propose a moderate correlation between the three components of attitude [22, 69]. However, it is possible for there to be differences between what people feel and think about specific robots, as is the case for some of the studies included in the present review [10, 70, 71]. The impact of dissonance between affective and cognitive attitudes in relation to human-robot interaction has not yet been investigated and warrants consideration.

Where studies used measures of attitude that did not reflect purely affective or cognitive attitudes, or it was not possible to obtain data for subscales measuring different outcomes (e.g., the NARS), we coded said measures under the blanket term of general attitudes. Findings for this outcome were not entirely consistent with the results for affective and cognitive attitudes, as the sample-weighted mean was almost zero and thus indicated a relatively neutral rather than slightly positive attitude. Indeed, compared to the other outcomes, the number of studies providing evidence for negative attitudes was much greater (i.e., approximately half of the studies). It is possible that this finding was a product of some difference in the methodology or measures that necessitated the studies' inclusion in the general category. For example, NARS subscales may have been combined if the reliability of the subscales was poor.

Although we coded the outcomes in the primary studies based on definitions rooted in social psychological research on attitudes (see Sect. 1.1), it should be noted that studies generally did not differentiate between the various types of attitudes and often did not provide a definition of attitudes at all. This may be of some concern especially if it indicates a poor understanding of the relationship between attitudes and behaviour. Given the number of studies that measured attitudes in the context of human-robot interaction [27, 39, 72] and sometimes with the purpose of predicting behaviour [24, 27, 39, 72-74], attitude-behaviour models from social psychology should be used more consistently to inform HRI research [75-77].

\subsection{To What Extent do People Accept, Trust, and Feel Anxious Toward Robots?}

We found that, in general, people are either willing to use social robots or have the intention to do so given the chance. Given the conceptual overlap between acceptance of social robots and behavioural attitudes, it is not surprising that our findings with respect to acceptance are similar to our findings for affective and cognitive attitudes. This is once again consistent with research supporting a moderate correlation between the three components of attitude [22, 69].

Findings from the studies measuring trust indicated that, in general, people neither explicitly trusted or mistrusted robots; rather they typically were neutral with respect to trust. However, given the variability in estimates of trust across studies (i.e., some studies reported high trust and others low trust) it is likely that the extent to which people trust social robots is moderated by other factors, some of which we discuss below in Sect. 6.3.

Finally, we found evidence suggesting that people are fairly neutral in terms of the anxiety that they report with respect to social robots. This finding may, to a certain extent, be a product of the general tendency for social robots to be designed in such a way as to appear less threatening. For example, NAO, a generally well-liked robot $[42,78,79]$, was used in $45 \%$ of the studies measuring anxiety and may have contributed to the overall neutral to positive valence for anxiety and trust.

\subsection{What Factors Affect the Main Outcomes?}

We found mixed evidence that exposure to robots, domain of application and design of the robots, and the age and gender of participants was associated with people's beliefs about robots. This was predominantly due to a limited number of studies which meant that it was not possible to reliably estimate beliefs for the different categories of many of the factors of interest. Indeed, affective attitudes was the only outcome for which it was possible to compare all categories across all the factors. Additionally, whether participants were exposed to robots (directly or indirectly) before their beliefs were measured was the only factor for which comparison across the outcome measures was possible. As such we will focus on these findings first.

We found mixed evidence on whether and how exposure to robots affects people's attitudes and beliefs. Participants typically reported positive affective attitudes regardless of whether they interacted with a robot or not. However, people's affective attitudes toward social robots in studies with indirect HRI were typically less positive than participants' 
affective attitudes in studies with no HRI or direct HRI. This suggests that interacting with a robot face-to-face elicits more positive feelings toward said robot (or robots in general) than does some form of indirect contact such as watching a video of the robot. These findings may be an important consideration when measuring attitudes in HRI contexts where the affective evaluation of a robotic platform during indirect contact may not accurately represent people's feelings toward that robot, or social robots in general $[72,80]$.

Notably, interaction did not seem to have the same effect on cognitive or general attitudes. For example, studies involving direct contact typically found that people held negative cognitive and general attitudes toward social robots. This finding is somewhat contrary to assertions that directly interacting with robots is a potential strategy for improving attitudes toward them $[51,72,81]$. It could be that while the novelty of directly interacting with a social robot results in positive affect it also allows participants to identify potential issues with robotic platforms or make general observations about their usefulness that result in negative thoughts. Supporting this idea is our finding that, unlike affective attitudes, participants typically reported more positive cognitive and general attitudes in studies utilising indirect contact (where it could be more difficult to identify issues with robotic platforms) than in studies with direct HRI. Due to a lack of studies utilising contact other than direct HRI, it was not possible to draw definitive conclusions regarding the impact of exposure to robots on people's acceptance of, anxiety toward, and trust in social robots.

Although we found some differences in participants' affective, cognitive, and general attitudes between geographical locations, these findings were limited by the number of studies available for comparison for nearly all outcomes. This was partly due to the fact that the majority of studies were either conducted in the USA, in Germany, or in Japan. As a consequence, the present review cannot draw conclusions about the influence of people's culture on their beliefs about social robots. Additionally, we would note that the geographical location in which the studies were conducted is only an approximation of participants' cultural background as most studies did not report this information. Even where the nationality and/or ethnicity of participants was reported, it may not necessarily reflect the participants' cultural background. The present review identified only six studies labelled as cross-cultural which may indicate a lack of cross-cultural research on people's attitudes toward social robots.

Similarly, our data and findings do not provide a strong enough base for conclusions regarding the extent to which the design (i.e., level of human-likeness) and application area of the robot moderated people's attitudes and anxiety toward, trust in, and acceptance of robots. We also found no evidence that the age of participants was associated with any of the outcomes despite existing empirical evidence to the contrary. Previous studies comparing young and elderly adults have demonstrated that, in general, older adults have more negative attitudes toward robots and are less willing to use robotic technology [65]. We did find evidence that the gender of participants was associated with the extent to which they trusted robots (in general, samples with a larger percentage of female participants reported more trust in robots). However, for most outcomes, the number of studies was quite small and it was difficult to draw clear conclusions regarding the effect of gender.

\subsection{Have Attitudes Changed Over Time?}

We found no evidence that beliefs about social robots have changed over time. However, the earliest paper in our review was published in 2005 and the majority of studies were published between 2014 and 2018. As such, our analysis was based on a rather constrained data set with the majority of data points falling within a four-year period. While we cannot say for certain whether people's beliefs about social robots have changed over time, we should probably first ask whether social robotics has existed long enough for such changes to have occurred at all.

One approach might be to consider the changes in attitudes, trust, and acceptance that have taken place in relation to robotics in general and past technological developments such as the modern computer and smartphones and then use these trends to predict how peoples' beliefs about social robots might change over time. For example, Gnambs and Appel [82] investigated changes in attitudes towards robotic systems within the European Union between 2012 and 2017. They found that, although attitudes toward various robotic systems were generally positive, there was a significant decrease in favourable opinions over the five-year period. Most notably, attitudes towards autonomous robots in the workplace were overall the most positive but also saw the largest negative shift in attitudes between 2012 and 2017. Gnambs and Appel proposed that the change in people's attitudes may be the result of increasing media coverage of robotic systems and growing fears about automation and its impact on the job market [2,3]. Therefore, although the present review suggests that people's attitudes toward social robots are typically slightly positive, it may be that we should expect a negative shift in attitudes over the coming years.

\subsection{Suggestions for Future Research}

The present review identifies a number of methodological issues that should be addressed by future research. Some of these limitations are not specific to the study of social robotics - for instance, the tendency to rely on samples of student volunteers. Although practical and financial limita- 
tions are often a barrier to the acquisition of more diverse sample groups, it is important to acknowledge the limitations of sampling procedures and consider potential bias when drawing conclusions. Where broader questions about the way that robots should be designed and integrated into specific domains are asked, it is important to acknowledge that making broader generalisations about the rest of society based on this limited sample of participants may not be appropriate. A further observation was the reliance on selfreport measures (typically multi-item Likert scales). While using self-report measures often makes sense and yields useful data, some consideration should be given to applying other types of measures alongside well-known scales such as the NARS, especially given the intention-behaviour gap in technology usage [83]. Indeed, there have been advances in both behavioural and/or physiological measures (e.g., of arousal) that may prove useful in future research.

Finally, we attempted to analyse the effect of previous experience with robots on participants' attitudes, as research has found that this might play a role in shaping people's beliefs about robots [54, 84, 85]. Although fourteen studies reported information about the extent to which participants had interacted with social robots previously, there was only one study in which more than half of the participants had seen or interacted with a robot before. The rest of the studies reported that the majority of participants had little to no experience with social robots. As such, the findings of our review should probably be considered a reflection of people's initial attitudes toward social robots; something that-given that most people rarely have any contact with social robot$\mathrm{s}$-is likely to currently reflect most people's attitudes toward social robots. Readers interested in the effect of long-term interactions on attitudes might consult a review by Leite, Martinho, and Paiva [54], which suggests that, while people are generally willing to interact with robots repeatedly, their attitudes may change over time.

\section{Conclusion}

The evidence presented in this review suggests that people-at least people who do not have extensive experience of social robots-generally have a positive view of social robots. More specifically, the evidence suggests that people typically have positive feelings and thoughts toward social robots and are willing to interact with robots should the chance present itself. These findings may help to alleviate some of the concerns regarding the likelihood that people will adopt robotics in socially focused domains such as healthcare and education. However, knowing that people typically have somewhat positive beliefs about social robots does not necessarily help us to predict the economic and social impacts of widely adopting this type of technology. A positive disposition is only one of a number of factors that may determine the landscape of human-robot relationships in the future and we suggest that applying theories of intergroup relations and attitude-behaviour models [75-77] to the study of social robotics might help to understand what these relationships may look like. Finally, although we may draw parallels between the progression and impact of other technology (such as computers) and social robotics, we should also acknowledge the qualities that mark social robots as not just another technological development but perhaps as an entire new social group with its own complexity [86].

Acknowledgements We are grateful to the authors who provided additional data about their research and for the support and advice from members of Sheffield Robotics. We are also grateful to Tracy Epton for her work on an earlier (non-systematic) review that provided the impetus for the present work. Tony Prescott's contribution to this paper was supported by the EU Horizon 2020 programme through the FET Flagship Human Brain Project (HBP-SGA1, 720270; HBP-SGA2, 785907). This research was part-supported by the Wellcome Trust [214963/A/18/Z].

\section{Compliance with Ethical Standards}

Conflict of interest Tony Prescott is a director and shareholder of the company Consequential Robotics that develops social robots and chair of the company Cyberselves that develops immersive technologies.

Open Access This article is licensed under a Creative Commons Attribution 4.0 International License, which permits use, sharing, adaptation, distribution and reproduction in any medium or format, as long as you give appropriate credit to the original author(s) and the source, provide a link to the Creative Commons licence, and indicate if changes were made. The images or other third party material in this article are included in the article's Creative Commons licence, unless indicated otherwise in a credit line to the material. If material is not included in the article's Creative Commons licence and your intended use is not permitted by statutory regulation or exceeds the permitted use, you will need to obtain permission directly from the copyright holder. To view a copy of this licence, visit http://creativecomm ons.org/licenses/by/4.0/.

\section{References}

1. European Commission (2012) Public attitudes towards robots

2. *Broadbent E, Tamagawa R, Patience A, Knock B, Kerse N, Day K, MacDonald BA (2012) Attitudes towards health-care robots in a retirement village. Aust J Ageing 31(2):115-120

3. Ebel KH (1986) The impact of industrial robots on the world of work. Int Lab Rev 125:39

4. Kriz S, Ferro TD, Damera P, Porter JR (2010) Fictional robots as a data source in HRI research: exploring the link between science fiction and interactional expectations. In: 19th international symposium on robot-human interactive communication. IEEE, pp 458-463

5. Ajzen I (1991) The theory of planned behavior. Organ Behav Hum Decis Process 50(2):179-211

6. Pieska S, Luimula M, Jauhiainen J, Spiz V (2013) Social service robots in wellness and restaurant applications. J Commun Comput 10(1):116-123 
7. Takeda T, Hirata Y, Kosuge K (2007) Dance step estimation method based on HMM for dance partner robot. IEEE Trans Ind Electron 54(2):699-706. https://doi.org/10.1109/TIE.2007.8916 42

8. Hancock PA, Billings DR, Schaefer KE, Chen JYC, de Visser EJ, Parasuraman R (2011) A meta-analysis of factors affecting trust in human-robot interaction. Hum Factors 53(5):517-527. https:// doi.org/10.1177/0018720811417254

9. Ray C, Mondada F, Siegwart R (2008) What do people expect from robots? In: 2008 IEEE/RSJ international conference on intelligent robots and systems. IEEE, pp 3816-3821

10. *Nomura T, Kanda T, Suzuki T (2006) Experimental investigation into influence of negative attitudes toward robots on human-robot interaction. AI Soc 20(2):138-150

11. Nørskov M (2017) Technological dangers and the potential of human-robot interaction: a philosophical investigation of fundamental epistemological mechanisms of discrimination. In: Social robotics. Routledge, pp 99-121

12. Zhao D, Yi J (2006) Robot planning with artificial potential field guided ant colony optimization algorithm. In: International conference on national computing. Springer, pp 222-231

13. Hegel F, Muhl C, Wrede B, Hielscher-Fastabend M, Sagerer G (2009) Understanding social robots. In: 2009 second international conference on advanced computer-humun interaction. IEEE, pp 169-174

14. Broekens J, Heerink M, Rosendal H (2009) Assistive social robots in elderly care: a review. Gerontechnol 8(2):94-103

15. Heerink M, Kröse B, Evers V, Wielinga B (2010) Assessing acceptance of assistive social agent technology by older adults: the almere model. Int J Soc Robot 2(4):361-375

16. Im I, Hong S, Kang MS (2011) An international comparison of technology adoption: testing the UTAUT model. Inf Manag 48(1): $1-8$

17. *Gaudiello I, Zibetti E, Lefort S, Chetouani M, Ivaldi S (2016) Trust as indicator of robot functional and social acceptance. An experimental study on user conformation to iCub answers. Comput Hum Behav 61:633-655

18. *Gombolay M, Yang XJ, Hayes B, Seo N, Liu Z, Wadhwania S, Shah J (2018) Robotic assistance in the coordination of patient care. Int J Robot Res 37(10):1300-1316. https://doi.org/10.1177/ 0278364918778344

19. *Herse S, Vitale J, Tonkin M, Ebrahimian D, Ojha S, Johnston B, Williams MA (2018) Do you trust me, blindly? Factors influencing trust towards a robot recommender system. In: 2018 27th IEEE international symposium on robot and human interactive communication (RO-MAN). https://doi.org/10.1109/roman.2018.85255 81

20. *Li D, Rau PP, Li Y (2010) A cross-cultural study: effect of robot appearance and task. Int J Soc Robot 2(2):175-186. https://doi. org/10.1007/s12369-010-0056-9

21. Enz S, Diruf M, Spielhagen C, Zoll C, Vargas PA (2011) The social role of robots in the future-explorative measurement of hopes and fears. Int J Soc Robot 3(3):263

22. Breckler SJ (1984) Empirical validation of affect, behavior, and cognition as distinct components of attitude. J Pers Soc Psychol 47(6): 1191

23. Nomura T, Kanda T, Yamada S, Suzuki T (2011) Exploring influences of robot anxiety into HRI. In: 2011 6th ACM/IEEE international conference on humun-robot interaction (HRI). IEEE, pp 213-214

24. *Nomura T, Kanda T, Suzuki T, Kato K (2008) Prediction of human behavior in human-robot interaction using psychological scales for anxiety and negative attitudes toward robots. IEEE Trans Robot 24(2):442-451

25. *Nomura T, Suzuki T, Kanda T, Kato K (2006) Measurement of anxiety toward robots. In: ROMAN 2006-the 15th IEEE interna- tional symposium robot humun interaction communication. IEEE, pp 372-377

26. *Nomura T, Shintani T, Fujii K, Hokabe K (2007) Experimental investigation of relationships between anxiety, negative attitudes, and allowable distance of robots. In: Proceedings of the second IASTED international conference on human computer interaction, Chamonix, France, ACTA Press

27. de Graaf MM, Allouch SB (2013) The relation between people's attitude and anxiety towards robots in human-robot interaction. In: 2013 IEEE RO-MAN. IEEE, pp 632-637

28. Salem M, Lakatos G, Amirabdollahian F, Dautenhahn K (2015) Would you trust a (faulty) robot? Effects of error, task type and personality on human-robot cooperation and trust. In: Proceedings of 10th annual ACM/IEEE international conference on human robot interaction. ACM, pp 141-148

29. Hall MA, Dugan E, Zheng B, Mishra AK (2001) Trust in physicians and medical institutions: what is it, can it be measured, and does it matter? Milbank Q 79(4):613-639

30. *Papers marked with an asterisk were included in the review

31. Hancock PA, Billings DR, Schaefer KE (2011) Can you trust your robot? Ergon Des 19(3):24-29

32. Davis FD (1989) Perceived usefulness, perceived ease of use, and user acceptance of information technology. MIS Q: 319-340

33. Venkatesh V, Morris MG, Davis GB, Davis FD (2003) User acceptance of information technology: toward a unified view. MIS Q: $425-478$

34. Broadbent E, Stafford R, MacDonald B (2009) Acceptance of healthcare robots for the older population: review and future directions. Int J Soc Robot 1(4):319

35. Dawe J, Sutherland C, Barco A, Broadbent E (2019) Can social robots help children in healthcare contexts? A scoping review. BMJ Paediatr Open 3(1)

36. Klamer T, Allouch SB (2010) Acceptance and use of a social robot by elderly users in a domestic environment. In: 2010 4th international conference on pervasive computing technologies for healthcare. IEEE, pp 1-8

37. *de Graaf MM, Allouch SB, Lutfi S (2016) What are people's associations of domestic robots? Comparing implicit and explicit measures. In: 2016 25th IEEE international symposium on robot and human interactive communication (RO-MAN). IEEE, pp $1077-1083$

38. *Reich-Stiebert N, Eyssel F, Hohnemann C (2019) Involve the user! Changing attitudes toward robots by user participation in a robot prototyping process. Comput Hum Behav 91:290-296

39. *Zlotowski JA, Sumioka H, Nishio S, Glas DF, Bartneck C, Ishiguro $H$ (2015) Persistence of the uncanny valley: the influence of repeated interactions and a robot's attitude on its perception. Front Psychol 6:883

40. May DC, Holler KJ, Bethel CL, Strawderman L, Carruth DW, Usher JM (2017) Survey of factors for the prediction of human comfort with a non-anthropomorphic robot in public spaces. Int $\mathrm{J}$ Soc Robot 9(2):165-180

41. Savela N, Turja T, Oksanen A (2018) Social acceptance of robots in different occupational fields: a systematic literature review. Int J Soc Robot 10(4):493-502

42. *Hosseini SMF, Lettinga D, Vasey E, Zheng Z, Jeon M, Park CH, Howard AM (2017) Both "look and feel" matter: Essential factors for robotic companionship. In: 2017 26th IEEE international symposium on robot and human interactive communication (RO-MAN). IEEE, pp 150-155

43. Torta E, Werner F, Johnson DO, Juola JF, Cuijpers RH, Bazzani M, Oberzaucher J, Lemberger J, Lewy H, Bregman J (2014) Evaluation of a small socially-assistive humanoid robot in intelligent homes for the care of the elderly. J Intell Robot Syst 76(1):57-71. https://doi.org/10.1007/s10846-013-0019-0 
44. *Alemi M, Meghdari A, Ghazisaedy M (2014) The effect of employing humanoid robots for teaching English on students' anxiety and attitude. In: 2014 2nd RSI/ISM international confernce on robot mechatron (ICRoM). IEEE, pp 754-759

45. *Carrillo FM, Butchart J, Kruse N, Scheinberg A, Wise L, McCarthy C (2018) Physiotherapists' acceptance of a socially assistive robot in ongoing clinical deployment. In: 2018 27th IEEE international symposium on robot and human interactive communication (RO-MAN). IEEE, pp 850-855

46. *Chang W-L, White JP, Park J, Holm A, Šabanović S (2012) The effect of group size on people's attitudes and cooperative behaviors toward robots in interactive gameplay. In: 2012 IEEE RO-MAN: The 21st IEEE international symposium on robot and human interactive communication. IEEE, pp 845-850

47. *Kim M-G, Lee J, Aichi Y, Morishita H, Makino M (2016) Effectiveness of robot exhibition through visitors experience: a case study of Nagoya Science Hiroba exhibition in Japan. In: 2016 international symposium on micro-nanomechatronics and human science (MHS). IEEE, pp 1-5

48. de *Graaf MM, Allouch SB (2013) Exploring influencing variables for the acceptance of social robots. Robot Auton Syst 61(12): 1476-1486

49. *Serholt S, Basedow CA, Barendregt W, Obaid M(2014) Comparing a humanoid tutor to a human tutor delivering an instructional task to children. In: 2014 IEEE-RAS international conference humun and robot. IEEE, pp 1134-1141

50. *Dunst CJ, Trivette CM, Prior J, Hamby DW, Embler D (2013) Parents' judgments of the acceptability and importance of socially interactive robots for intervening with young children with disabilities. Soc Robot Res Rep, number 1. Orelena Hawks Puckett Institute

51. *Bartneck C, Suzuki T, Kanda T, Nomura T (2007) The influence of people's culture and prior experiences with Aibo on their attitude towards robots. AI Soc 21(1-2):217-230

52. *Bartneck C, Nomura T, Kanda T, Suzuki T, Kato K (2005) Cultural differences in attitudes towards robots. In: Symposium on robot companions (SSAISB 2005 convention), Hatfield, pp 1-4

53. *Bernotat J, Eyssel F (2018) Can (' $\mathrm{t}$ ) wait to have a robot at home? - Japanese and German users' attitudes toward service robots in smart homes. In: 2018 27th IEEE international symposium on robot and human interactive communication (RO-MAN). https:// doi.org/10.1109/roman.2018.8525659

54. Leite I, Martinho C, Paiva A (2013) Social robots for long-term interaction: a survey. Int J Soc Robot 5(2):291-308. https://doi. org/10.1007/s12369-013-0178-y

55. Chen K, Chan AH (2011) A review of technology acceptance by older adults. Gerontechnol 10(1):1-12

56. Crites SL Jr, Fabrigar LR, Petty RE (1994) Measuring the affective and cognitive properties of attitudes: conceptual and methodological issues. Personal Soc Psychol Bull 20(6):619-634

57. *Dinet J, Vivian R (2014) Exploratory investigation of attitudes towards assistive robots for future users. Le Travail Humain 77(2):105-125

58. Conti D, Di Nuovo S, Buono S, Di Nuovo A (2017) Robots in education and care of children with developmental disabilities: a study on acceptance by experienced and future professionals. Int J Soc Robot 9(1):51-62. https://doi.org/10.1007/s12369-016-035 9-6

59. *Shin D-H, Choo H (2011) Modeling the acceptance of socially interactive robotics: social presence in human-robot interaction. Interact Stud 12(3):430-460

60. *Tay B, Jung Y, Park T (2014) When stereotypes meet robots: the double-edge sword of robot gender and personality in human-robot interaction. Comput Hum Behav 38:75-84

61. *Nomura T (2014) Influences of experiences of robots into negative attitudes toward robots. In: The 23rd IEEE interna- tional symposium on robot and human interactive communication. IEEE, pp 460-464

62. *Fridin M, Belokopytov M (2014) Acceptance of socially assistive humanoid robot by preschool and elementary school teachers. Comput Hum Behav 33:23-31

63. *Wu Y-h, Wrobel J, Cornuet M, Kerhervé H, Damnée S, Rigaud A-S (2014) Acceptance of an assistive robot in older adults: a mixed-method study of human-robot interaction over a 1-month period in the Living Lab setting. Clin Interv Aging 9:801

64. *Kuchenbrandt D, Eyssel F (2012) The mental simulation of a human-robot interaction: positive effects on attitudes and anxiety toward robots. In: 2012 IEEE RO-MAN: the 21st IEEE international symposium on robot and human interactive communication. IEEE, pp 463-468

65. *Wullenkord R, Eyssel F (2014) Improving attitudes towards social robots using imagined contact. In: The 23rd IEEE international symposium on robot and human interactive communication. IEEE, pp 489-494

66. *Stanton CJ, Stevens CJ (2017) Don't stare at me: the impact of a humanoid robot's gaze upon trust during a cooperative human-robot visual task. Int J Soc Robot 9(5):745-753

67. *Cramer H, Kemper N, Amin A, Wielinga B, Evers V (2009) 'Give me a hug': the effects of touch and autonomy on people's responses to embodied social agents. Comput Animat Virtual Worlds 20(2-3):437-445

68. *Reich-Stiebert N, Eyssel F (2015) Learning with educational companion robots? Toward attitudes on education robots, predictors of attitudes, and application potentials for education robots. Int J Soc Robot 7(5):875-888

69. Ostrom TM (1969) The relationship between the affective, behavioral, and cognitive components of attitude. J Exp Soc Psychol $5(1): 12-30$

70. *Backonja U, Hall AK, Painter I, Kneale L, Lazar A, Cakmak M, Thompson HJ, Demiris G (2018) Comfort and attitudes towards robots among young, middle-aged, and older adults: a crosssectional study. J Nurs Scholarsh 50(6):623-633

71. Rantanen T, Lehto P, Vuorinen P, Coco K (2018) Attitudes towards care robots among Finnish home care personnel-a comparison of two approaches. Scand J Caring Sci 32(2):772-782. https://doi. org/10.1111/scs 12508

72. *Wullenkord R, Fraune MR, Eyssel F, Šabanović S (2016) Getting in touch: how imagined, actual, and physical contact affect evaluations of robots. In: 2016 25th IEEE international symposium on robot and human interactive communication (RO-MAN). IEEE, pp 980-985

73. *Park E, Del Pobil AP (2012) An acceptance model for service robots in global markets. Int J Hum Robot 9(04):1250026

74. *Spence PR, Edwards A, Edwards C (2018) Attitudes, prior interaction, and petitioner credibility predict support for considering the rights of robots. In: Companion of the 2018 ACM/IEEE international conference on human-robot interaction. ACM, pp 243-244

75. Pettigrew TF (1998) Intergroup contact theory. Annu Rev Psychol 49(1):65-85

76. Pratto F, Sidanius J, Levin S (2006) Social dominance theory and the dynamics of intergroup relations: taking stock and looking forward. Eur Rev Soc Psychol 17(1):271-320

77. Hewstone M, Swart H (2011) Fifty-odd years of inter-group contact: from hypothesis to integrated theory. Br J Soc Psychol 50(3):374-386

78. Rosenthal-Von Der Pütten AM, Krämer NC (2014) How design characteristics of robots determine evaluation and uncanny valley related responses. Comput Hum Behav 36:422-439

79. *Torta E, Oberzaucher J, Werner F, Cuijpers RH, Juola JF (2013) Attitudes towards socially assistive robots in intelligent homes: 
results from laboratory studies and field trials. J Hum Robot Interact 1(2):76-99

80. *Bazzano F, Lamberti F (2018) Human-robot interfaces for interactive receptionist systems and way finding applications. Robot 7(3):56

81. Stafford R, Broadbent E, Jayawardena C, Unger U, Kuo IH, Igic A, Wong R, Kerse N, Watson C, MacDonald BA (2010) Improved robot attitudes and emotions at a retirement home after meeting a robot. In: 19th international symposium on robot and human interactive communication. IEEE, pp 82-87

82. Gnambs T, Appel M (2019) Are robots becoming unpopular? Changes in attitudes towards autonomous robotic systems in Europe. Comput Hum Behav 93:53-61. https://doi.org/10.1016/ j.chb.2018.11.0

83. Bhattacherjee A, Sanford C (2009) The intention-behaviour gap in technology usage: the moderating role of attitude strength. Behav Inf Technol 28(4):389-401

84. Syrdal DS, Dautenhahn K, Koay KL, Ho WC (2014) Views from within a narrative: evaluating long-term human-robot interaction in a naturalistic environment using open-ended scenarios. Cogn Comput 6(4):741-759. https://doi.org/10.1007/s12559-01 4-9284-X

85. Kachouie R, Sedighadeli S, Khosla R, Chu MT (2014) Socially assistive robots in elderly care: a mixed-method systematic literature review. Int J Hum Robot Interact 30(5):369-393. https://doi. org $/ 10.1080 / 10447318.2013 .873278$

86. Prescott TJ (2017) Robots are not just tools. Connect Sci 29(2):142-149

87. Dediu H (2015) Personal computer. Asymco. http://www.asymco. com/2015/04/14/personal-computer. Accessed 8 Oct 2019

88. McKitterick W (2016) The global smartphone report: the forces behind the global deceleration in smartphone sales. Bus Insider India. https://www.businessinsider.in/THE-GLOBALSMARTPHONE-REPORT-The-forces-behind-the-globaldeceleration-in-smartphone-sales/articleshow/52018367.cms. Accessed 8 Oct 2019

89. Turkle S, Helmreich S (2009) Simulation and its discontents. MIT Press, London

90. Turkle S (2005) The second self: computers and the human spirit. MIT Press, London

91. *Avelino J, Moreno P, Bernardino A, Correia F, Paiva A, Catarino J, Ribeiro P (2018) The power of a hand-shake in human-robot interactions. In: 2018 IEEE/RSJ international conference on intelligent robots and systems (IROS), Madrid, Spain, pp 1864-1869

92. *Barnes J, Richie E, Lin Q, Jeon M, Park C H (2018) Emotive voice acceptance in human-robot interaction. In: The 24th international community for auditory displays (ICAD)

93. *Birnbaum GE, Mizrahi M, Hoffman G, Reis HT, Finkel EJ, Sass O (2016) Machines as a source of consolation: robot responsiveness increases human approach behavior and desire for companionship. In: ACM/IEEE international conference on human-robot interaction (HRI), pp 165-172. https://doi.org/10.1 109/HRI20167451748

94. *Broadbent E, Kerse N, Peri K, Robinson H, Jayawardena C, Kuo T, MacDonald B (2016) Benefits and problems of health-care robots in aged care settings: a comparison trial. Aust J Ageing 35(1):23-29. https://doi.org/10.1111/ajag.12190

95. *Cameron D, Millings A, Fernando S, Collins EC, Moore R, Sharkey A, Prescott T (2018) The effects of robot facial emotional expressions and gender on child-robot interaction in a field study. Connect Sci 30(4):343-361. https://doi.org/10.1080/0954 009120181454889

96. *Carter EJ, Mistry MN, Carr GPK, Kelly BA, Hodgins JK (2014) Playing catch with robots: Incorporating social gestures into physical interactions. In: The 23rd IEEE international symposium on robot and human interactive communication, Edinbrugh, UK, pp 231-236. https://doi.org/10.1109/roman.2014.6926258

97. *Cavallo F, Esposito R, Limosani R, Manzi A, Bevilacqua R, Felici E, Dario P (2018) Acceptance of robot-era system: results of robotic services in smart environments with older adults. J Med Internet Res. https://doi.org/10.2196/jmir.9460

98. *Chang RCS, Lu HP, Yang P (2018) Stereotypes or golden rules? Exploring likable voice traits of social robots as active aging companions for tech-savvy baby boomers in Taiwan. Comput Hum Behav 84:194-210. https://doi.org/10.1016/jchb201802025

99. *Coco KPRN, Kangasniemi MP, Rantanen TP (2018) Care personnel's attitudes and fears toward care robots in elderly care: a comparison of data from the care personnel in Finland and Japan. J Nurs Scholarsh 50(6):634-644. https://doi.org/10.1111/jnu.124 35

100. *Conti D, Cattani A, Di Nuovo S, Di Nuovo A (2015) A cross-cultural study of acceptance and use of robotics by future psychology practitioners. In: IEEE conference, pp 555-560. https://doi.org/10.1109/ROMAN20157333601

101. *Correia F, Guerra C, Mascarenhas S, Melo FS, Paiva A (2018) Exploring the impact of fault justification in human-robot trust. In: Proceedings of the 17th international conference on autonomous agents and multiagent systems, Stockholm, Sweden

102. *Damholdt MF, Nørskov M, Yamazaki R, Hakli R, Hansen CV, Vestergaard C, Seibt J (2015) Attitudinal change in elderly citizens toward social robots: the role of personality traits and beliefs about robot functionality. Front Psychol 6:1701. https://doi.org/10.338 9/fpsyg201501701

103. *Erebak S, Turgut T (2018) Caregivers' attitudes toward potential robot coworkers in elder care. Cognit Technol Work. https://doi. org/10.1007/s10111-018-0512-0

104. *Eyssel F, Kuchenbrandt D, Bobinger S, de Ruiter L, Hegel F (2012) 'If you sound like me, you must be more human': On the interplay of robot and user features on human-robot acceptance and anthropomorphism In: Proceedings 7th annual ACM/IEEE international conference on human-robot interaction. https://doi. org/10.1145/2157689.2157717

105. *Eyssel F, Kuchenbrandt D, Hegel F, de Ruiter L (2012) Activating elicited agent knowledge: how robot and user features shape the perception of social robots In: The 2012 IEEE RO-MAN: 21 st IEEE international symposium on robot and human interactive communication. https://doi.org/10.1109/roman.2012.634385 8

106. *Ezer N, Fisk AD, Rogers WA (2009) Attitudinal and intentional acceptance of domestic robots by younger and older adults. In: International conference on universal access in human-computer interaction. https://doi.org/10.1007/978-3-642-02710-9_5

107. *Fischer K, Weigelin HM, Bodenhagen L (2018) Increasing trust in human-robot medical interactions: effects of transparency and adaptability. Paladyn J Behav Robot 9(1):95-109. https://doi.org/ 10.1515/pjbr-2018-0007

108. *Haring KS, Silvera-Tawil D, Matsumoto Y, Velonaki M, Watanabe K (2014) Perception of an android robot in japan and australia: a cross-cultural comparison. In: International conference on robotics society. https://doi.org/10.1007/978-3-319-1197 3-1_17

109. *Haring K S, Silvera-Tawil D, Takahashi T, Velonaki M, Watanabe K (2015) Perception of a humanoid robot: a cross-cultural comparison In: 2015 24th IEEE international symposium on robot and human interactive communication (RO-MAN). https://doi. org/10.1109/roman.2015.7333613

110. *Haring KS, Silvera-Tawil D, Takahashi T, Watanabe K, Velonaki M (2016) How people perceive different robot types: a direct comparison of an android, humanoid, and non-biomimetic robot In: 2016 8th international conference knowledge and smart technology (KST). https://doi.org/10.1109/kst.2016.7440504 
111. *Iwamura Y, Shiomi M, Kanda T, Ishiguro H, Hagita N (2011) Do elderly people prefer a conversational humanoid as a shopping assistant partner in supermarkets? In: 2011 6th ACM/IEEE international conference on human robot interaction (HRI). https://doi. org/10.1145/1957656.1957816

112. *Khan S, Germak C (2018) Reframing HRI design opportunities for social robots: lessons learnt from a service robotics case study approach using UX for HRI. Future internet 10(10) https://doi. org/10.3390/fi10100101

113. *Kim KJ, Park E, Shyam Sundar S (2013) Caregiving role in human-robot interaction: a study of the mediating effects of perceived benefit and social presence. Comput Hum Behav 29(4):1799-1806. https://doi.org/10.1016/j.chb.2013.02.009

114. *Kraus M, Kraus J, Baumann M, Minker W (2018) Effects of gender stereotypes on trust and likability in spoken human-robot interaction. In: Proceedings of 11th international conference on language resources and evaluation (LREC-2018), pp 112-118

115. *Kuo IH, Rabindran JM, Broadbent E, Lee YI, Kerse N, Stafford RMQ, MacDonald BA (2009) Age and gender factors in user acceptance of healthcare robots. In: RO-MAN 2009 18th IEEE international symposium on robot and human interactive communication, Toyama, Japan. https://doi.org/10.1109/roman.2009.53 26292

116. *Liang YJ, Lee SA (2016) Advancing the strategic messages affecting robot trust effect: the dynamic of user- and robotgenerated content on human-robot trust and interaction outcomes. Cyberpsychol Behav Soc Netw 19(9):538-544. https://doi.org/1 0.1089/cyber.2016.0199

117. *Louie WYG, McColl D, Nejat G (2014) Acceptance and attitudes toward a human-like socially assistive robot by older adults. Assist Technol Off J RESNA 26(3):140-150. https://doi.org/10.1080/1 04004352013869703

118. *Lugrin B, Dippold J, Bergmann K (2018) Social robots as a means of integration? An explorative acceptance study considering gender and non-verbal behaviour. In: 2018 IEEE/RSJ international conference on intelligent robots (IROS), Madrid, Spain, pp 2026-2032. https://doi.org/10.1109/iros.2018.859381 8

119. *Macdorman KF, Vasudevan SK, Ho CC (2009) Does Japan really have robot mania? Comparing attitudes by implicit and explicit measures. AI Soc 23(4):485-510. https://doi.org/10.1007/s0014 6-008-0181-2

120. *Matsui T, Yamada S (2018) Robot's impression of appearance and their trustworthy and emotion richness. In: 2018 27th IEEE international symposium on robot and human interactive communication (RO-MAN), Nanjing, China, pp 88-93. https://doi.org/1 0.1109/roman.2018.8525796

121. *Mavridis N, Katsaiti MS, Naef S, Falasi A, Nuaimi A, Araifi H, Kitbi A (2012) Opinions and attitudes toward humanoid robots in the Middle East. AI Soc 27(4):517-534. https://doi.org/10.1007/ s00146-011-0370-2

122. *Miller KF, Self WH, McNaughton CD, Mion LC, Storrow AB (2012) Attitudes toward health care robot assistants in the ED: a survey of ED patients and visitors: 211. Acad Emerg Med April 2012; 19 Supplement 1:S116

123. *Mirnig N, Stadler S, Stollnberger G, Giuliani M, Tscheligi M (2016) Robot humor: How self-irony and Schadenfreude influence people's rating of robot likability. In: 2016 25th IEEE international symposium on robot and human interactive communication (RO-MAN), Columbia University, NY, USA. https:// doi.org/10.1109/ROMAN.2016.7745106

124. *Nomura T (2017) Cultural differences in social acceptance of robots. In: 2017 26th IEEE international symposium on robot and human interactive communication (RO-MAN), Lisbon, Portugal, pp 534-538. https://doi.org/10.1109/roman.2017.8172354
125. *Park E, Kwon SJ (2016) The adoption of teaching assistant robots: a technology acceptance model approach. Program 50(4):354-366. https://doi.org/10.1108/PROG-02-2016-0017

126. *Park E, Lee J (2014) I am a warm robot: the effects of temperature in physical human-robot interaction. Robotica 32(1):133-142. https://doi.org/10.1017/S026357471300074X

127. *Pino M, Boulay M, Jouen F, Rigaud A-S (2015) "Are we ready for robots that care for us?" Attitudes and opinions of older adults toward socially assistive robots. Front Aging Neurosci. https:// doi.org/10.3389/fnagi201500141

128. *Robert D, van den Bergh V (2014) Children's openness to interacting with a robot scale (COIRS). In: 23rd IEEE international symposium on robot and human interactive communication, Edinburgh, Scotland, UK, pp 930-935. https://doi.org/10.1109/roman. 2014.6926372

129. *Salem M, Eyssel F, Rohlfing K, Kopp S, Joublin F (2013) To err is human (-like): effects of robot gesture on perceived anthropomorphism and likability. Int J Soc Robot 5(3):313-323. https:// doi.org/10.1007/s12369-013-0196-9

130. *Stadler S, Weiss A, Tscheligi M (2014) I trained this robot: the impact of pre-experience and execution behavior on robot teachers. In: 23rd IEEE international symposium on robot and human interactive communication, Edinburgh, Scotland, UK, pp 1030-1036. https://doi.org/10.1109/roman.2014.6926388

131. *Stuck RE, Rogers WA (2018) Older adults' perceptions of supporting factors of trust in a robot care provider. J Robot. https:// doi.org/10.1155/2018/6519713

132. *Sundar S, Waddell T, Jung EH (2016) The hollywood robot syndrome media effects on older adults' attitudes toward robots and adoption intentions. In: ACM/IEEE international conference on human robot interaction (HRI), pp 343-350. https://doi.org/10.1 109/HRI20167451771

133. *Tung F-W (2016) Child perception of humanoid robot appearance and behavior. Int J Hum Comput Interact 32(6):493-502. https://doi.org/10.1080/10447318.2016.1172808

134. van den *Brule R, Dotsch R, Bijlstra G, Wigboldus DH, Haselager P (2014) Do robot performance and behavioral style affect human trust? Int J Soc Robot 6(4):519-531. https://doi.org/10.1007/s12 369-014-0231-5

135. *Volante WG, Sosna J, Kessler T, Sanders T, Hancock P (2018) Social conformity effects on trust in simulation-based human-robot interaction. Hum Factors 61(5):805-815. https:// doi.org/10.1177/0018720818811190

136. *Weiss A, Bernhaupt R, Tscheligi M, Wollherr D, Kuhnlenz K, Buss M (2008) A methodological variation for acceptance evaluation of human-robot interaction in public places. In: Proceedings of the 17th IEEE international symposium on robot and human interactive communication, Technische Universität München, Munich, Germany, pp 713-718. https://doi.org/10.110 9/roman.2008.4600751

137. *Weiss A, Bernhaupt R, Tscheligi M, Yoshida E (2009) Addressing user experience and societal impact in a user study with a humanoid robot. In: AISB2009: proceedings of symposium on new frontiers in human-robot interaction, Edinburgh, UK, pp $150-157$

Publisher's Note Springer Nature remains neutral with regard to jurisdictional claims in published maps and institutional affiliations.

Stanislava Naneva is a $\mathrm{PhD}$ candidate in the Department of Psychology at the University of Sheffield, UK. Her current research focuses on the impact of fictional and non-fictional representations of robots on people's attitudes. 
Marina Sarda Gou is a PhD candidate in the Department of Psychology at the University of Sheffield, UK. Her research includes humanrobot interaction and attitude studies. One of her current projects is on the effect of direct and extended contact in attitudes towards social humanoid robots.

Thomas L. Webb is a Professor of Psychology at the University of Sheffield, UK. His research focuses on self-regulation - how people control their thoughts, feelings, and actions in order to achieve their goals. He has recently been extending this work to consider how social psychology can be used to understand how people think about and interact with robots.
Tony J. Prescott is a Professor of Cognitive Robotics at the University of Sheffield, and Director of Sheffield Robotics, a cross-disciplinary research institute with over two hundred researchers. His background mixes psychology, neuroethology and brain theory with robotics and AI, and his current research focuses are on brain-based robotics, human-robot interaction, and societal impacts of robotics and AI, particularly in the domains of education and healthcare. He has cofounded two companies, Consequential Robotics Ltd, which develops educational and assistive robots including the animal-like social robot, Miro, and Cyberselves Ltd which develops robotic telepresence systems. 